\title{
HACIA NUEVOS DERECHOS HUMANOS EN LA ERA DE LA NEUROCIENCIA Y LA NEUROTECNOLOGÍA***
}

\section{Towards New Human Rights in the Age of Neuroscience and Neurotechnology}

\author{
MARCELLO IENCA ${ }^{a}$ \\ https://orcid.org/0000-0001-8835-5444 \\ marcello.ienca@hest.ethz.ch \\ ROBERTO ANDORNo ${ }^{b}$ \\ https://orcid.org/0000-0003-2070-8703 \\ roberto.andorno@uzh.ch
}

${ }^{a}$ Swiss Federal Institute of Technology Zurich (ETH), Dept. of Health Sciences and Technology, Zurich, Switzerland

${ }^{b}$ School of Law \& Institute of Biomedical Ethics and History of Medicine, University of Zurich, Zurich, Switzerland

\section{Resumen}

Los rápidos avances en neurociencia y neurotecnología abren un conjunto de posibilidades sin precedentes en el acceso, colecta, diseminación y manipulación de datos del cerebro humano. Estos desarrollos plantean importantes desafíos a los derechos humanos que deben abordarse para evitar consecuencias no deseadas. Este trabajo evalúa las implicaciones de los diferentes usos de las neurotecnologías en relación a los derechos humanos y sugiere que el marco actual de derechos humanos puede no ser suficiente para responder a estos desafíos emergentes. Después de analizar la relación entre neurociencia y derechos humanos, identificamos cuatro nuevos derechos que pueden ser de gran relevancia en las próximas décadas: el derecho a la libertad cognitiva, el derecho a la privacidad mental, el derecho a la integridad mental y el derecho a la continuidad psicológica.

* El presente artículo fue publicado originariamente en inglés con el título "Towards new human rights in the age of neuroscience and neurotechnology" en la revista Life Sciences, Society and Policy, 2017, 13(5). La versión original está disponible en: https:// lsspjournal.springeropen.com/articles/10.1186/s40504-017-0050-1. Traducción de Abel Wajnerman Paz, Universidad Alberto Hurtado, Santiago de Chile, Chile.

** Quedo muy agradecido con Marcello Ienca y Roberto Andorno por su amable permiso para traducir el trabajo, que considero esencial a efectos del avance de la discusión, profundización e implementación de los neuroderechos que se está dando en Latinoamérica. A su vez, quiero expresar un especial agradecimiento a Roberto Andorno por sus extensos y detallados comentarios, revisiones y actualizaciones de la presente traducción (Nota del T.). 


\begin{abstract}
Rapid advancements in human neuroscience and neurotechnology open unprecedented possibilities for accessing, collecting, sharing and manipulating information from the human brain. Such applications raise important challenges to human rights principles that need to be addressed to prevent unintended consequences. This paper assesses the implications of emerging neurotechnology applications in the context of the human rights framework and suggests that existing human rights may not be sufficient to respond to these emerging issues. After analysing the relationship between neuroscience and human rights, we identify four new rights that may become of great relevance in the coming decades: the right to cognitive liberty, the right to mental privacy, the right to mental integrity, and the right to psychological continuity.
\end{abstract}

Tú no puedes afectar la libertad de mi mente (Thou canst not touch the freedom of my mind)

John Milton

\title{
Introducción
}

La cita del epígrafe es de la obra Comus, escrita por John Milton en 1634. La pieza, una exhortación a la virtud, sigue la historia de una joven noble que fue secuestrada por un hechicero llamado Comus. Luego de atarla a una silla encantada, trata de seducirla con argumentos sobre el encanto del placer corporal. A pesar de todos sus asaltos retóricos, la mujer rechaza repetidamente sus avances y afirma que, sin importar lo que él haga o diga, ella continuará afirmando su libertad de pensamiento, que está más allá del poder físico de su secuestrador. Al final, la joven es rescatada por sus hermanos, que ahuyentan a Comus.

La frase citada transmite la idea de que la mente es una especie de último refugio de la libertad personal y la autodeterminación. Mientras que el cuerpo puede ser fácilmente sujeto a la dominación y al control de los demás, nuestra mente, junto con nuestros pensamientos, creencias y convicciones, están en gran medida más allá de los ataques externos. Sin embargo, con los avances en ingeniería neuronal, neuroimágenes y neurotecnología, la mente podría ya no ser una fortaleza tan inexpugnable. Como explicaremos en este artículo, las nuevas neurotecnologías tienen el potencial de permitir el acceso a al menos algunos componentes de la información mental. Si bien estos avances pueden ser muy beneficiosos para los individuos y la sociedad, también pueden ser mal utilizados y crear amenazas sin precedentes a la libertad mental y a la capacidad de los individuos de gobernar libremente su comportamiento. 
En el contexto de la investigación médica, las neuroimágenes se utilizan ampliamente para comprender el funcionamiento del cerebro humano y detectar los correlatos neuronales de los estados mentales y el comportamiento. Las aplicaciones clínicas de las imágenes cerebrales, así como de otras neurotecnologías, están contribuyendo significativamente al bienestar de pacientes que sufren trastornos neurológicos, ofreciendo nuevas herramientas preventivas, diagnósticas y terapéuticas. Fuera del ámbito clínico, nuevas aplicaciones comerciales están generando nuevas posibilidades de auto-cuantificación, mejora cognitiva, comunicación personalizada y entretenimiento. Además, varias aplicaciones de la neurotecnología están captando interés en el ámbito jurídico, especialmente en el derecho de responsabilidad civil, el derecho penal y la ejecución de la ley.

Por otra parte, el mal uso o implementación inadecuada de estas tecnologías implican el riesgo de crear formas sin precedentes de intrusión en la esfera privada de las personas, potencialmente causando un daño físico o psicológico, o permitiendo una influencia indebida en el comportamiento de las personas.

Este artículo argumenta que las posibilidades abiertas por los desarrollos neurotecnológicos y su aplicación a diversos aspectos de la vida humana obligarán a reconceptualizar ciertos derechos humanos, o incluso a crear nuevos derechos para proteger a la gente de daños potenciales.

En 2013, el presidente Obama de los EE.UU. llamó la atención sobre el impacto potencial de la neurociencia sobre los derechos humanos, destacando la necesidad de abordar cuestiones como aquellas

(...) relacionadas con la privacidad, la capacidad de acción y la responsabilidad moral respecto de nuestras acciones; preguntas sobre la estigmatización y la discriminación basadas en medidas neurológicas de inteligencia u otros rasgos; y preguntas sobre el uso apropiado de la neurociencia en el sistema de justicia penal (Comisión Presidencial para el Estudio de Cuestiones Bioéticas, 2014).

Este artículo comienza explorando las posibilidades y desafíos actuales de la neurotecnología y considera qué tendencias neurotecnológicas impulsarán esta reconceptualización ética y legal. Después de analizar cuidadosamente la relación entre la neurociencia y los derechos humanos, se identifican cuatro nuevos derechos que pueden llegar a ser relevantes en las próximas décadas: el derecho a la libertad cognitiva, el derecho a la privacidad mental, el derecho a la integridad mental y el derecho a la continuidad psicológica. 


\section{La revolución neurotecnológica}

Durante mucho tiempo, los límites del cráneo han sido considerados generalmente como la línea de separación entre la dimensión observable y la inobservable de los seres humanos vivos. De hecho, aunque formas primitivas de neurocirugía utilizadas en las sociedades antiguas, incluidos los procedimientos pseudocientíficos como la trepanación, podían permitir la observación e incluso la manipulación (por ejemplo, la eliminación selectiva) del tejido cerebral, los procesos neuronales y mentales que se desarrollan en el cerebro y subyacen a las emociones, el razonamiento y el comportamiento permanecieron por mucho tiempo inobservables. En contraste, los avances modernos en la neurociencia y la neurotecnología han permitido el desbloqueo progresivo del cerebro humano y proporcionaron información sobre los procesos cerebrales, así como sobre su relación con los estados mentales y el comportamiento observable. En 1878, Richard Canton descubrió la transmisión de señales eléctricas a través del cerebro de un animal. Cuarenta y seis años después, se registró la primera electroencefalografía (EEG) humana. Desde entonces, la revolución neurotecnológica ha tenido lugar dentro y fuera de la clínica. En los años 1990, a veces llamada "la década del cerebro", el uso de técnicas de imágenes para estudios neuroconductuales aumentó drásticamente (Illes, 2003). Hoy en día, mientras un amplio espectro de tecnologías de neuroimágenes se ha vuelto clínica y comercialmente disponible, el registro y la visualización no invasivas de patrones de actividad cerebral (a menudo asociados con la realización de tareas físicas o cognitivas) se ha convertido en una práctica estándar. Por ejemplo, los registros de EEG se están utilizando ampliamente para medir de forma no invasiva la actividad eléctrica del cerebro y detectar fluctuaciones de voltaje. Además, los derivados de la técnica de EEG, como los potenciales evocados (EP, por las siglas en inglés ${ }^{1}$ ) y los potenciales relacionados con evento (ERP), permiten promediar las respuestas del EEG a la presentación y procesamiento de los estímulos, y así registrar las señales del cerebro durante el desempeño de tareas sensoriales, cognitivas o motoras específicas. Otra técnica, la resonancia magnética funcional (fMRI), permite medir la actividad eléctrica del cerebro de forma indirecta, esto es, utilizando las respuestas hemodinámicas (el flujo sanguíneo cerebral) como marcadores indirectos. Las técnicas actuales de fMRI pueden localizar la actividad cerebral, representar gráficamente los patrones de activación neuronal, y determinan su intensidad codificando por medio

${ }^{1}$ En lo que sigue, todas las siglas refieren a los nombres en inglés (N. del T.). 
de colores la fuerza de la activación. Estas se implementan para una variedad de propósitos que incluyen la evaluación de riesgos antes de una cirugía, el mapeo funcional de áreas del cerebro para detectar anomalías (por ejemplo, asimetría hemisférica en las regiones del lenguaje y la memoria), el monitoreo de la recuperación después de un accidente cerebrovascular o de una cirugía, así como los efectos de terapias farmacológicas y de comportamiento. Además, un número de condiciones neurológicas como la depresión y la enfermedad de Alzheimer ahora pueden ser diagnosticadas por medio del uso de fMRI (Koch et al., 2012).

Se ha probado que la capacidad de las técnicas de neuroimágenes de mapear las funciones del cerebro es también eficaz en la obtención de información sobre las intenciones, puntos de vista y actitudes de las personas. Por ejemplo, se pudo inferir qué acciones tenían la intención de realizar los participantes de un experimento a partir de la decodificación de su actividad cerebral. La tarea en cuestión consistía en decidir si sumar o restar dos números y mantener encubierta su intención por unos pocos segundos. Durante ese lapso de tiempo, los científicos pudieron determinar con un $70 \%$ de precisión cuál de las dos tareas los sujetos intentaban realizar encubiertamente (Haynes et al., 2007). En otro estudio, los participantes recorrieron primero varias casas en un espacio de realidad virtual, y luego sus cerebros fueron escaneados mientras recorrían otro conjunto de casas. Al identificar ciertos patrones de actividad cerebral para cada casa, los científicos pudieron determinar cuáles eran las casas en las que los sujetos habían estado antes (Smith, 2013). Los escáneres cerebrales no sólo permiten "leer" las intenciones y recuerdos concretos relacionados con un experimento, sino que parecen incluso ser capaces de decodificar preferencias más generales. Un estudio estadounidense ha demostrado que la resonancia magnética puede utilizarse para deducir las opiniones políticas de los usuarios identificando diferencias funcionales entre los cerebros de demócratas y republicanos (Schreiber et al., 2013). De manera similar, la frecuente preferencia de los hombres por coches deportivos se ha correlacionado con diferencias funcionales específicas entre los cerebros de hombres y mujeres (Baron-Cohen 2004).

La posibilidad de identificar de forma no invasiva los correlatos mentales de diferencias cerebrales funcionales es de particular interés para el marketing. Hace más de una década, McClure y otros (2004) utilizaron fMRI para mostrar diferencias funcionales (mayor activación en la corteza prefrontal dorsolateral, el hipocampo y el mesencéfalo) entre el cerebro de personas bebiendo Coca Cola a sabiendas y el cerebro de las mismas personas bebiendo Coca Cola sin etiquetar. Sus resultados 
mostraron que las diferentes estrategias de marketing (por ejemplo, la etiqueta de Coca Cola) pueden determinar diferentes respuestas en el cerebro de los consumidores (McClure et al., 2004). Estos resultados fueron pioneros en el establecimiento de una rama de la neurociencia en la intersección con la investigación en marketing llamada 'neuromarketing', que se ha expandido rápidamente durante la década pasada. Hoy en día, varias empresas multinacionales como Google, Disney, CBS, y Frito-Lay utilizan los servicios de investigación en neuromarketing para medir las preferencias e impresiones de los consumidores respecto de sus anuncios o productos. Además, un número de compañías especializadas en neuromarketing incluyendo EmSense, Neurosence, MindLab International y Nielsen, aplican rutinariamente técnicas de neuroimágenes, principalmente fMRI y EEG, pero también topografía de estado estable (SST en inglés) y mediciones fisiológicas (por ejemplo, la respuesta galvánica de la piel) para estudiar, analizar y predecir el comportamiento del consumidor. La posibilidad de una extracción de datos de la mente (o al menos de aspectos estructurales de la mente ricos en información) puede ser potencialmente utilizada no solo para inferir las preferencias mentales, sino también para incitar, implantar $o$ activar esas preferencias. Por ejemplo, Neurofocus, una empresa multinacional americana de neuromarketing recientemente adquirida por Nielsen, probó técnicas subliminales con el fin de producir respuestas (por ejemplo, preferir un ítem A en lugar de uno B) que las personas no pueden registrar conscientemente (Penenberg, 2011). Estas técnicas presuponen insertar estímulos de menos de 30 milisegundos, bajo el umbral de la percepción consciente. En vista de estos desarrollos, se ha subrayado la necesidad de establecer normas éticas y jurídicas para las prácticas de neuromarketing (Ulman, Cakar y Yildiz, 2015).

Las técnicas de imágenes cerebrales se desarrollaron originalmente, y todavía se aplican en su mayoría, en el contexto de la medicina clínica y la investigación neurocientífica. Sin embargo, en los últimos años, una serie de aplicaciones neurotecnológicas se han abierto camino en el mercado y están ahora integradas a un conjunto de dispositivos de consumo para usuarios sanos con diversos con fines no clínicos. El término genérico que se suele utilizar para englobar a todas estas neurotecnologías no invasivas, escalables y potencialmente ubicuas es "neurotecnología omnipresente" (pervasive neurotechnology, Fernández et al., 2015), una noción derivada de la más extendida de "computación omnipresente". Hoy en día, las aplicaciones dominantes de la neurotecnología incluyen interfaces cerebro-computadora (BCIs) para el control de dispositivos o la neuromonitorización en tiempo real, sistemas de 
operación de vehículos a partir de neurosensores, herramientas de entrenamiento cognitivo, sistemas de estimulación magnética o eléctrica del cerebro, dispositivos portátiles para el bienestar mental y sistemas de realidad virtual.

La mayoría de estas aplicaciones usan registros de EEG que monitorean la actividad eléctrica en el cerebro para una variedad de propósitos, incluyendo la neuromonitorización (evaluación en tiempo real del funcionamiento del cerebro), el entrenamiento neurocognitivo (usando ciertas bandas de frecuencia para mejorar las funciones neurocognitivas) y el control de dispositivos. Los BCIs basados en EEG se están usando cada vez más como accesorios portátiles para un número de actividades diarias incluyendo juegos, entretenimiento y el control remoto de teléfonos inteligentes. Por ejemplo, las empresas Emotiv y Neurosky ofrecen un gran surtido de cascos inalámbricos para uso diario que se pueden conectar a teléfonos inteligentes compatibles y computadoras personales (Ienca \& Haselager, 2016). El control cerebral puede ser usado para controlar a distancia varios tipos de dispositivos y realizar varias actividades, incluidos juegos y otras formas de entretenimiento, marketing, automonitoreo y comunicación.

La posibilidad de un control cerebral no invasivo ha captado la atención de la industria de la comunicación móvil. Varias compañías líderes, incluyendo Apple y Samsung, han incorporado dispositivos neuronales (neurogadgets) entre los accesorios de sus productos principales. Por ejemplo, accesorios de iPhone como el casco XWave ya pueden conectarse directamente a iPhones compatibles y leer las ondas cerebrales. Mientras tanto, el control por medio de actividad cerebral a través de BCIs basados en EEG ya se ha probado en los prototipos de próxima generación de tablets de Samsung Galaxy y otros dispositivos móviles o portátiles (Powell et al., 2013). A la luz de estas tendencias, Yuan y colegas predijeron que los dispositivos neurológicos reemplazarán gradualmente el teclado, la pantalla táctil y el ratón como la forma preferida de los humanos para interactuar con las computadoras (Yuan et al., 2010).

No solo los dispositivos de neuroimágenes y las BCIs entran en la categoría de la neurotecnología omnipresente. Varios estimuladores eléctricos del cerebro también encajan en esta categoría. A diferencia de las neuroimágenes, los neuroestimuladores no se utilizan principalmente para registrar o decodificar el cerebro sino para estimular o modular eléctricamente la actividad cerebral. Dispositivos portátiles y fáciles de usar de estimulación transcraneal de corriente directa (tDCS) son la forma más extendida de neuroestimulador de consumidor. Se utilizan en una serie de aplicaciones de bajo costo dirigidas al consumidor, destina- 
das a optimizar el rendimiento del cerebro en una variedad de tareas cognitivas, dependiendo de la región del cerebro que se esté estimulando. ${ }^{2}$ Recientemente, la estimulación magnética transcraneal (TMS), un método magnético utilizado para estimular brevemente pequeñas regiones del cerebro para fines tanto diagnósticos como terapéuticos, también ha sido implementada en dispositivos portátiles, lo que resultó eficaz para el tratamiento de la migraña (Lefaucheur et al., 2014). Finalmente, una técnica quirúrgica invasiva llamada estimulación cerebral profunda (DBS) que implica la implantación de un neuroestimulador en el núcleo ventral intermedio del tálamo, ha obtenido la aprobación de la FDA y ahora se utiliza cada vez más como tratamiento para el temblor esencial, la enfermedad de Parkinson, la distonía y el trastorno obsesivo-compulsivo.

En resumen, si en las últimas décadas la neurotecnología ha desbloqueado el cerebro humano y lo ha hecho legible bajo lentes científicos, las próximas verán a la neurotecnología convertirse en omnipresente, inmersa en numerosos aspectos de nuestras vidas y cada vez más eficaz en modular los correlatos neuronales de nuestros procesos mentales y comportamiento. Mientras que alentamos el progreso continuo en el desarrollo de la neurotecnología, en este trabajo argumentamos que las implicaciones éticas y legales de la revolución neurotecnológica deben ser consideradas tempranamente y de una manera proactiva. Más específicamente, sostenemos que el sistema legal tiene que estar adecuadamente preparado para hacer frente a los nuevos desafíos que podrían surgir de la neurotecnología emergente, en particular en el contexto de los derechos humanos. A medida que la neurotecnología avanza, es crucial evaluar si el marco actual de derechos humanos está conceptual y normativamente bien equipado para enfrentar los nuevos desafíos que surgen del entrelazamiento cerebro-computadora-sociedad, para dar simultáneamente orientación a los investigadores y a los desarrolladores de tecnología, al mismo tiempo que proteger a individuos y grupos.

\section{La tecnología del cerebro y el derecho}

La neurociencia y el derecho se cruzan en muchos niveles y en varias cuestiones diferentes. Esto no es sorprendente. Mientras que la neurociencia estudia los procesos cerebrales que subyacen al comportamiento humano, los sistemas legales se ocupan por antonomasia de

\footnotetext{
${ }^{2}$ Por ejemplo, el sitio web The Brain Stimulator ofrece un amplio surtido de dispositivos tDCS, con precios que oscilan entre 60 y 200 dólares. Véase: https:// thebrainstimulator.net/shop/
} 
la regulación del comportamiento humano. Por lo tanto, es razonable afirmar que ambas disciplinas están destinadas a ser "aliadas naturales" (Goodenough \& Tucker, 2010). La idea subyacente al nuevo campo llamado "neuroderecho" (neurolaw) es precisamente que un mejor conocimiento del cerebro llevará a un mejor diseño de las leyes y a procedimientos legales más justos. Los ejemplos de aplicaciones de la neurotecnología potencialmente pertinentes desde el punto de vista jurídico son numerosos. Las técnicas de imágenes cerebrales, por ejemplo, podrían contribuir a decisiones en el marco de procedimientos penales que estén basadas en evidencia, tanto en la investigación y la evaluación de la responsabilidad penal, como en el castigo, la rehabilitación de los delincuentes y la evaluación de su riesgo de reincidencia. Las herramientas que ofrece la neurociencia podrían desempeñar también un papel en los procedimientos de derecho civil, por ejemplo, en la evaluación de la capacidad de un individuo para celebrar un contrato, o de la severidad del dolor en las demandas de indemnización de daños. Nuevas y más fiables tecnologías de detección de mentiras basadas en el conocimiento del funcionamiento del cerebro podrían ayudar a evaluar la fiabilidad de testigos. La supresión de memorias de criminales violentos reincidentes y de las víctimas de delitos especialmente traumáticos (por ejemplo, el abuso sexual), son otra posibilidad que abre nuestro nuevo conocimiento del cerebro (Goodenough \& Tucker, 2010).

Aharoni y otros (2013) han señalado un posible uso de la neurotecnología en el campo legal que podría tener un gran impacto. En su estudio, los investigadores siguieron a un grupo de 96 prisioneros varones luego de su liberación. Usando fMRI, los cerebros de los prisioneros fueron escaneados durante la realización de tareas computacionales en las que tenían que tomar decisiones rápidas e inhibir reacciones impulsivas. Los investigadores siguieron luego a los ex-convictos durante 4 años para ver cómo se comportaban. Los resultados del estudio indican que aquellos individuos que muestran una baja actividad en una región del cerebro asociada con la toma de decisiones y la acción, la corteza cingulada anterior, tienen una mayor probabilidad de volver a cometer delitos dentro de los cuatro años siguientes a su liberación (Aharoni et al., 2013). Según el estudio, el riesgo de reincidencia es más del doble en los individuos que muestran una baja actividad en esa región del cerebro que en los individuos con alta actividad en esa región. Sus resultados sugieren un "potencial biomarcador neurocognitivo para el comportamiento antisocial persistente". En otras palabras, los escáneres cerebrales pueden ayudar teóricamente a determinar si ciertos convictos tienen un mayor riesgo de reincidencia tras ser liberados. 
Esta posibilidad evoca la historia de ciencia ficción de Philip Dick de 1956 "The Minority Report", que fue adaptada a una película de 2002. La trama trata de una unidad especial de la policía ("División Precrimen") que es capaz de identificar y detener a asesinos antes de que cometan sus crímenes. El sistema parecía funcionar perfectamente hasta que un oficial de esa misma unidad es acusado, por error, de un futuro crimen (Dick, 2002). Este escenario distópico, que podría resultar de los nuevos conocimientos sobre el cerebro, plantea importantes cuestiones éticas y de derechos humanos ¿Cuán seguro es que los escáneres cerebrales solo permitirán identificar a los delincuentes de alto riesgo? ¿Pueden los datos generados por la neurotecnología, que tienen una naturaleza probabilística, aplicarse directamente para predecir el comportamiento criminal de un individuo en particular? ¿Pueden estas conclusiones preliminares, que se basaron en una cohorte muy específica, ser generalizadas a otros grupos? En cualquier caso, está claro que se necesitan muchos más estudios para asegurar la fiabilidad de la técnica antes de autorizar su uso por los tribunales, ciertamente no como sustituto de los métodos actuales de evaluación de la peligrosidad, pero tal vez como una herramienta adicional y complementaria.

Otras tecnologías cerebrales que pueden ser relevantes para el sistema legal son los detectores de mentiras, los decodificadores mentales y las huellas cerebrales. Los detectores de mentiras son dispositivos capaces de registrar y medir las respuestas cerebrales asociadas a la recuperación de los recuerdos, con el propósito de determinar los valores de verdad de las declaraciones relativas a esos recuerdos. Los detectores de mentiras tradicionales, como el polígrafo, miden algunos marcadores corporales como la presión sanguínea, la frecuencia cardíaca y las reacciones musculares. A pesar de su baja fiabilidad, son utilizados regularmente por algunas agencias gubernamentales para investigar a sus empleados. Sin embargo, muy raramente son aceptados como prueba en los tribunales de EE.UU. Las nuevas generaciones de detectores de mentiras, que están basados en EEG y fMRI, se consideran mucho más fiables que el polígrafo, ya que detectan la mentira en su origen: el cerebro. En los Estados Unidos, al menos dos compañías -No Lie MRI y Cephos Corp- están actualmente ofreciendo servicios de detección de mentiras por medio de fMRI (Greely, 2009). Un estudio publicado en 2005 por un grupo de investigación vinculado a Cephos, afirmó que la detección de mentiras basada en fMRI tiene una fiabilidad de alrededor del 90\%. El estudio predijo que el procedimiento se mejorará aún más y estará listo para ser utilizado en los tribunales en un futuro no muy lejano (Kozel et al., 2005). Estudios más recientes 
han confirmado la mayor fiabilidad de detectores de mentiras basados fMRI en comparación con la poligrafía (Langleben et al., 2016). Por su parte, los decodificadores mentales son capaces de decodificar estados mentales y transformarlos en outputs observables como texto, señales verbales o imágenes gráficas. Por ejemplo, Herff y otros (2015) y Mirkovic y otros (2015) han demostrado, en forma separada, la eficacia de un decodificador capaz de reconstruir el habla a partir de ondas cerebrales. Esos dispositivos tienen un gran potencial de aplicación clínica en tanto podrían beneficiar a varias clases de pacientes neurológicos, especialmente aquellos que sufren de síndrome de enclaustramiento y parálisis. Tales pacientes, que podrían haber perdido su capacidad de comunicarse verbalmente, serían capaces de interactuar con el mundo exterior produciendo habla solo por medio de la actividad cerebral. Fuera del contexto clínico, tales decodificadores se están probando para mejorar la comunicación móvil a través de conversores de pensamiento a texto. No todos los decodificadores mentales están diseñados para mejorar la autonomía de los usuarios. Algunos dispositivos están actualmente siendo probados para monitorear los estados cerebrales con el propósito de guiar el comportamiento del individuo. Por ejemplo, la NASA y Jaguar están desarrollando conjuntamente una tecnología llamada Mind Sense, que medirá las ondas cerebrales para monitorear la concentración del conductor de un auto (Biondi \& Skrypchuk, 2017). Si la actividad cerebral indica una mala concentración, entonces el volante o los pedales podrían vibrar para concientizar al conductor del peligro. Esta tecnología puede contribuir a reducir el número de accidentes causados por conductores estresados o distraídos. Sin embargo, también abre teóricamente la posibilidad de que terceros utilicen decodificadores cerebrales para espiar los estados mentales de las personas.

Implicaciones similares surgen en relación a los decodificadores de huellas cerebrales (brain printers). Estos son dispositivos prototípicos que se están probando actualmente como métodos de autenticación basados en el cerebro. Por ejemplo, investigadores de la Universidad de Binghamton en el estado de Nueva York han ideado una forma de verificar la identidad basada en cómo el cerebro responde a ciertas palabras. Los investigadores observaron las señales cerebrales de 45 voluntarios mientras leían una lista de 75 acrónimos, como FBI y DVD, y registraron la reacción de cada cerebro a cada grupo de letras, centrándose en la parte del cerebro asociada con la lectura y el reconocimiento de palabras. Resulta que los cerebros de los participantes reaccionaron de forma diferente a cada acrónimo, de modo que un sistema computacional fue capaz de identificar a cada voluntario con 
una precisión del 94\% (Armstrong et al., 2015). Esta tecnología, que podría sustituir a corto plazo a las contraseñas y las huellas dactilares como instrumento de autenticación para las cuentas personales, plantea novedosos problemas de privacidad y seguridad.

A medida que la neurotecnología avanza y abre nuevas oportunidades para el control y el seguimiento de la función cognitiva, existe incertidumbre sobre cómo la ley debe actuar frente a tales avances. En particular, sigue siendo discutible si las nuevas tendencias en neurotecnología requieren una revisión o incluso una sustitución de los conceptos jurídicos existentes en diversos niveles, entre ellos el derecho civil (en especial, el derecho de daños), el derecho comercial y la filosofía jurídica. Aunque cada vez se presta más atención en la literatura a las aplicaciones de la neurotecnología emergente en el contexto del derecho penal o al creciente uso de pruebas neurocientíficas en los tribunales, poco énfasis se ha puesto en las implicaciones de los avances de la neurociencia y la neurotecnología respecto de los derechos humanos. Este componente descuidado del discurso del neuroderecho es de particular relevancia, ya que la naturaleza universal del marco de los derechos humanos podría proporcionar un sólido fundamento para este emergente "derecho de la mente".

\section{Neurociencia y derechos humanos}

\section{Panorama general}

Aunque la neurotecnología tiene potencial para impactar de modo especial en ciertos derechos humanos tales como la privacidad, la libertad de pensamiento, la integridad mental, el derecho a no ser discriminado, el derecho a un juicio justo o el derecho a no autoincriminarse, el derecho internacional de los derechos humanos no hace ninguna referencia explícita a la neurociencia. A diferencia de otros desarrollos biomédicos que ya han sido objeto de esfuerzos normativos a nivel nacional e internacional, la neurotecnología sigue siendo en gran medida una terra incognita para el derecho internacional de los derechos humanos. No obstante, las implicaciones de la neurociencia y la neurotecnología respecto de características inherentes de los seres humanos instan a una respuesta rápida y flexible del derecho en este ámbito.

La capacidad de adaptación que las normas de derechos humanos han mostrado para responder a los desafíos planteados por la genética puede ayudar a anticipar cómo podría evolucionar esta rama del derecho en los próximos años en respuesta a las nuevas cuestiones plantea- 
das por la neurociencia. Desde fines de la década de 1990, la comunidad internacional ha hecho importantes esfuerzos para abordar una gran variedad de cuestiones que resultan del creciente acceso a los datos genéticos humanos. En 1997, la Declaración Universal sobre el Genoma Humano y los Derechos Humanos (UDHGHR) fue adoptada para evitar que la información genética se reúna y se utilice de maneras que son incompatibles con el respeto a los derechos humanos y para proteger al genoma humano de manipulaciones inapropiadas que pueden dañar a las generaciones futuras. Los principios contenidos en este instrumento fueron luego desarrollados en 2003 por la Declaración Internacional sobre Datos Genéticos Humanos (IDHGD), que establece normas más específicas para la recolección de muestras biológicas humanas y datos genéticos. Es interesante observar que la interacción entre la genética y los derechos humanos dio lugar a derechos totalmente nuevos, como el "derecho a no conocer la propia información genética", que está formalmente reconocido por la UDHGHR (Art. 5 (c)) y la IDHGD (Art. 10), así como por otros organismos internacionales y regulaciones nacionales. Además del reconocimiento de nuevos derechos, los "viejos" derechos como el derecho a la privacidad y el derecho a no ser objeto de discriminación- se adaptaron específicamente a los novedosos desafíos que plantea la genética. Esta estrecha conexión entre las ciencias de la vida y los derechos humanos se reforzó aún más con la Declaración Universal sobre Bioética y los Derechos Humanos de 2005, que aborda de manera exhaustiva el vínculo entre ambos campos (Andorno, 2013). Este último documento establece principios que son aplicables no solo a la genética, sino a otras cuestiones biomédicas y de las ciencias de la vida.

En este trabajo afirmamos que, de manera similar a la trayectoria histórica de la "revolución genética", la actual "neurorrevolución" remodelará algunas de nuestras nociones éticas y legales. En particular, argumentamos que la creciente eficiencia y disponibilidad de los neurodispositivos requerirá en los próximos años del surgimiento de nuevos derechos, o al menos del desarrollo de los derechos tradicionales, para abordar los desafíos específicos que plantean la neurociencia y la neurotecnología. Este argumento está de acuerdo con la observación sobre cómo los derechos humanos han surgido y se han desarrollado históricamente en las sociedades modernas. Los derechos humanos de hecho siempre han surgido como respuestas específicas a las recurrentes amenazas a intereses humanos fundamentales (Nickel, 1987), a la dignidad humana (Habermas, 2010), o a lo que requiere una "vida mínimamente buena" (Fagan, 2005). Como intentamos mostrar en este trabajo, la búsqueda individual del control sobre la propia dimensión 
neurocognitiva, así como la aparición de amenazas potenciales a bienes o intereses humanos básicos que plantea el uso indebido o la aplicación inadecuada de dispositivos neurotecnológicos, pueden requerir una reconceptualización de algunos derechos humanos tradicionales 0 incluso la creación de nuevos derechos neuroespecíficos.

Va más allá del alcance de este artículo discutir las diferentes teorías sobre los fundamentos de los derechos humanos o tomar una posición al respecto. A los efectos de nuestra investigación, elegimos adoptar una amplia concepción práctica de los derechos humanos, como la propuesta por Beitz (2011, p. 109), que argumenta que los derechos son "requisitos cuyo objeto es proteger intereses individuales urgentes contra peligros previsibles ('amenazas estándar') a los que son vulnerables en circunstancias típicas de la vida en el orden mundial moderno compuesto de Estados". En términos generales, se puede decir que el alcance de los derechos humanos es garantizar los requisitos negativos y positivos necesarios para llevar una vida mínimamente buena (Fagan, 2015).

Una objeción común contra el reconocimiento de nuevos derechos es que lleva a la llamada "inflación de derechos", que es la objetable tendencia a etiquetar como "derecho humano" todo lo que es moralmente deseable. La proliferación injustificada de nuevos derechos es en efecto problemática porque difunde un escepticismo sobre todos los derechos humanos, como si fueran simplemente expresiones de deseo o afirmaciones puramente retóricas. La inflación de derechos debe evitarse porque diluye la idea central de los derechos humanos y distrae de su objetivo central, que es proteger un conjunto de intereses humanos verdaderamente fundamentales y no todo lo que sería deseable o ventajoso en un mundo ideal.

Una forma generalmente aceptada de evitar la inflación de derechos es imponer pruebas justificativas para nuevos derechos humanos específicos. Por ejemplo, según Nickel (2014), podría exigirse que un derecho humano propuesto no solo se refiera a algún bien jurídico muy importante, sino también que responda a una amenaza común y grave a ese bien; que las cargas que imponga a los destinatarios sean justificadas y no mayores de lo necesario; y que sean factibles de implementar en la mayoría de los países (Nickel, 2014). El académico de derecho internacional Philip Alston (1984) ha sugerido una lista de criterios que debe cumplir un supuesto nuevo derecho para poder ser considerado como un verdadero derecho humano según el derecho internacional. En su opinión, el nuevo derecho humano propuesto debe "reflejar un valor social de importancia fundamental"; "ser coherente con el cuerpo existente del 
derecho internacional de derechos humanos, pero no meramente repetitivo de los derechos existentes"; "ser capaz de lograr un grado muy alto de consenso internacional", y "ser suficientemente preciso como para dar lugar a derechos y obligaciones identificables".

Por las razones que exponemos a continuación, creemos que los nuevos derechos que se defienden en este trabajo -el derecho a la libertad cognitiva, el derecho a la privacidad mental, el derecho a la integridad mental y el derecho a la continuidad psicológica- cumplen con estos requisitos y por lo tanto no corren el riesgo de contribuir a la inflación de derechos humanos.

Esta propuesta de derechos humanos neuroespecíficos es consistente con la defensa de Glen Boire de un "derecho de la mente" que "tiene en cuenta los últimos conocimientos sobre el cerebro" y "que sitúa a estos dentro de la tradición de nuestro país de apoyar al individuo, a la autodeterminación y al gobierno limitado" (Boire, 2003, p. 10). Como la tecnología del cerebro está reformando rápidamente la infoesfera y las infraestructuras digitales en nuestras sociedades, hay una necesidad urgente de determinar proactivamente si nuestros actuales marcos éticos y legales están listos para enfrentar este escenario emergente.

Vale la pena señalar aquí que muchos de los temas tratados en este trabajo no son exclusivos de la neurotecnología de vanguardia, sino que tienen precedentes en intervenciones más tradicionales. Por ejemplo, las violaciones de la privacidad mental surgieron antes de la invención de las tecnologías de neuroimagen y las tecnologías de neuromonitoreo, a través de técnicas más rudimentarias como el interrogatorio y las pruebas de polígrafo. Estas intervenciones, sin embargo, no se dirigen directamente al procesamiento neuronal, sino solo indirectamente a través de procesos substitutos como el habla, el comportamiento y los marcadores fisiológicos (por ejemplo, el pulso y la conductividad de la piel). Además, el grado de precisión y resolución de dichas técnicas es notablemente bajo (Iacono, 2008), por lo que a menudo es insuficiente para apoyar inferencias epistemológicamente justificadas sobre la información mental. De manera similar, las amenazas a la integridad mental y a la continuidad psicológica surgieron a partir de intervenciones no computacionales como las drogas psicoactivas y las inducciones hipnóticas mucho antes de la invención de la neuroestimulación y de las interfaces cerebro-máquina. Sin embargo, estas técnicas se caracterizan a menudo por una limitada eficacia y fiabilidad en la manipulación intencional de la actividad mental, así como por un bajo grado de precisión en la selección de los procesos neuronales. Basándonos en estas consideraciones, argumentamos que la neurotecnología avanzada 
permite un grado de acceso y manipulación de procesos neuronales significativamente más alto que otras técnicas. Por lo tanto, mientras consideramos al análisis ético y jurídico presentado en este trabajo como aplicable a todas las intervenciones cerebrales, tanto computacionales como no computacionales, argumentamos que el impacto de la neurotecnología avanzada respecto del marco ético-legal actual es cuantitativamente mayor que el de las técnicas no computacionales. Es por este motivo que situamos a la neurotecnología como el foco de nuestra propuesta de actualización normativa.

\section{La libertad cognitiva}

Un primer paso esencial hacia la creación de un marco neuroorientado de derechos humanos ha sido el reciente debate sobre la noción de libertad cognitiva. Según Bublitz (2013), esta noción compleja, a menudo también llamada "autodeterminación mental", comprende dos principios fundamentales e íntimamente relacionados: a) el derecho de las personas a utilizar las nuevas neurotecnologías; b) la protección de las personas contra el uso coercitivo y no consentido de tales tecnologías. Como afirmó concisamente Bublitz, la libertad cognitiva es el principio que garantiza "el derecho a alterar los estados mentales de uno con la ayuda de las herramientas neurocientíficas, así como a negarse a hacerlo" (Bublitz, 2013, p. 234).

Los partidarios de la libertad cognitiva sugieren considerarla también como un "derecho humano fundamental", como "un principio jurídico central que guíe la regulación de las neurotecnologías" (Bublitz, 2013 , p. 234). La razón de su función fundamental se deriva del hecho de que "el derecho y la libertad de controlar la propia conciencia y los propios procesos electroquímicos de pensamiento son el sustrato necesario para cualquier otra libertad" (Sententia, 2004). De hecho, como argumentó Bublitz, "es difícil articular cualquier concepción de un sujeto jurídico en la que la mente y las capacidades mentales (por ejemplo, actuar a partir de razones o la deliberación) no se encuentren entre sus condiciones constitutivas necesarias" (2013, p. 242). La libertad cognitiva, por lo tanto, es necesaria para todas las demás libertades porque es su sustrato neurocognitivo. Como tal, la libertad cognitiva se asemeja a la noción de "libertad de pensamiento" que suele considerarse como la justificación esencial de otras libertades, como la libertad de elección, la libertad de expresión, la libertad de prensa y la libertad religiosa. No es sorprendente que Sententia (2004) presente a la libertad cognitiva como una actualización conceptual de la libertad de pensamiento que 
"tiene en cuenta el poder que tenemos ahora, y tendremos cada vez en mayor medida, de vigilar y manipular la función cognitiva". Algunos estudiosos del derecho como Boire y Sententia han interpretado el derecho a la libertad cognitiva con especial énfasis en la protección de la libertad individual y la autodeterminación respecto del Estado. Por ejemplo, Sententia ha afirmado que "el Estado no puede, de acuerdo con la Primera Enmienda de la Constitución, manipular por la fuerza los estados mentales, e implícitamente los estados cerebrales de los ciudadanos individuales".

Dada su complejidad conceptual, la libertad cognitiva es multidimensional. Bublitz reconoce al menos tres "dimensiones interrelacionadas, pero no idénticas" (Bublitz, 2013, p. 251). Estas son: i) la libertad de modificar la propia mente o de elegir si y por qué medio modificar la propia mente; ii) la protección de las intervenciones sobre otras mentes para proteger la integridad mental, y iii) la obligación ética y jurídica de promover la libertad cognitiva. Estas tres dimensiones configuran la libertad cognitiva como un derecho complejo que implica los requisitos previos de las libertades tanto negativas como positivas en el sentido de Berlin (1959): la libertad negativa de tomar decisiones sobre el propio dominio cognitivo en ausencia de obstáculos, barreras o prohibiciones gubernamentales o no gubernamentales; la libertad negativa de ejercer el propio derecho a la integridad mental en ausencia de restricciones o violaciones de las corporaciones, los agentes criminales o el gobierno; y finalmente, la libertad positiva de tener la posibilidad de actuar de tal manera que podamos tomar el control nuestra vida mental.

Siendo el sustrato neurocognitivo de todas las demás libertades, la libertad cognitiva no puede ser reducida a los derechos existentes, por lo que es inmune al riesgo de inflación de los derechos. Además, ya que la vida cognitiva, aunque en varias formas y grados, es inherente a todos los humanos, la libertad cognitiva es coherente con una definición de los derechos humanos como inalienables derechos fundamentales que "le corresponden inherentemente a una persona por el simple hecho de ser un ser humano" (Sepuldeva et al., 2004), independientemente de su nacionalidad, ubicación, idioma, religión, origen étnico o cualquier otra condición. En consecuencia, su integración al marco de los derechos humanos permitiría la protección de características constitutivas de los seres humanos que no están totalmente protegidas por los derechos existentes.

A los efectos de nuestro análisis, en este artículo nos centraremos exclusivamente en la formulación negativa del derecho a la libertad cognitiva, es decir, el derecho a rechazar usos coercitivos de la neuro- 
tecnología. Además, aunque apoyamos la introducción del derecho a la libertad cognitiva, argumentamos que esta noción no es suficiente por sí sola para cubrir todas las implicaciones éticas y legales asociadas a la neurotecnología. Más bien, el establecimiento de la libertad cognitiva como un derecho humano debería coordinarse con una reconceptualización de los derechos existentes o incluso la creación de otros nuevos derechos neuroespecíficos. Estos son el derecho a la privacidad mental, el derecho a la integridad mental y el derecho a la continuidad psicológica.

\section{El derecho a la privacidad mental}

\section{El derecho a la privacidad}

Hoy, la infoesfera es más intrusiva que en cualquier otro momento de la historia. Los sitios web regularmente utilizan cookies para registrar información de los visitantes, así como sus actividades de navegación, preferencias, datos personales, páginas visitadas, contraseñas, números de tarjetas de crédito, etc. Grandes y pequeñas empresas se dedican a actividades de minería de datos que capturan cantidades masivas de datos sobre los usuarios. Gran parte de esta información es sobre actividades diarias: lo que se compró, cuándo, dónde y cuánto se pagó. Las cuentas de correo electrónico están llenas de anuncios y ofertas no solicitadas. Los números de teléfono y las direcciones personales son capturados en bases de datos y se venden a corporaciones y agencias gubernamentales. Además, la vigilancia por vídeo, la tecnología de reconocimiento facial, los programas espía están poniendo las actividades diarias de la gente a disposición del público. Como dice Moore (2010), hoy en día "la privacidad de la información está en todas partes bajo asedio".

La amplia disponibilidad de aplicaciones neurotecnológicas proporcionará múltiples oportunidades para que los individuos accedan a su actividad cerebral y ejerzan control sobre ella, lo que resultará en una serie de actividades potencialmente beneficiosas como la autovigilancia, la mejora neuronal y el control cerebral de sistemas computacionales. Sin embargo, estas mismas herramientas diseminarán un volumen y una variedad de información cerebral sin precedentes fuera del ámbito clínico y aumentarán potencialmente la disponibilidad de esa información para terceros. Al introducir los datos del cerebro en la infoesfera, las aplicaciones neurotecnológicas omnipresentes los están exponiendo al mismo grado de intrusión y vulnerabilidad a que se expone cualquier otra pieza de información que circula por el ecosistema 
digital. Actualmente, ninguna salvaguardia legal o técnica específica impide que los datos del cerebro sean sometidos a las mismas medidas de minería de datos y de intrusión en la privacidad que afectan a otros tipos de informaciones. En palabras de Nita Farahany, "no hay protecciones legales respecto de la lectura involuntaria de la mente". ${ }^{3}$ La razón de ello se deriva del hecho de que, como observa Charo (2005), "la innovación tecnológica es más rápida que la capacidad de adaptación del sistema regulativo".

Un gran número de cuestiones éticas, legales y sociales surgen de estas posibilidades, tales como: ¿con qué propósitos y bajo qué condiciones se puede recoger y utilizar informaciones del cerebro? ¿Qué componentes de la información cerebral pueden ser legítimamente revelados y puestos a disposición de terceros? ¿Quién tendrá derecho a acceder a esos datos (empleadores, compañías de seguros, el Estado)? ¿Cuáles deberían ser los límites de consentimiento en esta área?

Aunque se puede hacer un primer intento de respuesta a estas preguntas apelando a las normas jurídicas existentes, afirmamos que hay que desarrollar nociones y disposiciones jurídicas específicas. La primera noción implicada en estos debates es la de privacidad. El derecho internacional de derechos humanos reconoce formalmente el derecho a la privacidad. La Declaración Universal de los Derechos Humanos (UDHR) establece que "nadie será objeto de injerencias arbitrarias en su vida privada, su familia, su domicilio o su correspondencia, ni de ataques a su honra o a su reputación. Toda persona tiene derecho a la protección de la ley contra tales injerencias o ataques" (Artículo 12). Del mismo modo, la Convención Europea de Derechos Humanos (ECHR) de 1950 estipula que "toda persona tiene derecho al respeto de su vida privada y familiar, de su domicilio y de su correspondencia" (párrafo 1 del artículo 8). Es interesante observar que el derecho a la privacidad es uno de los pocos derechos reconocidos internacionalmente como un derecho amplio y general antes de ser incluido en cualquier constitución estatal (Diggelmann \& Cleis, 2014).

A nivel europeo, el derecho a la privacidad reconocido por la ECHR fue desarrollado por la Directiva para la Protección de Datos de la UE de 1995 (95/46/CE), que tiene como objetivo específico la protección de las personas en lo que respecta al procesamiento y la transferencia de sus datos personales. Recientemente, la UE ha adaptado las normas de

\footnotetext{
${ }^{3}$ Discurso en el panel sobre "What If: Your Brain Confesses?", World Economic Forum - Annual Meeting, Davos, 20-23 de enero de 2016. Disponible en: https://www. weforum.org/events/world-economic-forum-annual-meeting-2016/sessions/what-ifyour-brain-confesses
} 
protección de datos a los desafíos a la privacidad que plantea el nuevo entorno digital. El objetivo general del nuevo Reglamento es permitir a las personas tener más control sobre sus datos personales. ${ }^{4}$

A su vez, la Carta de Derechos Fundamentales de la Unión Europea, adoptada en 2000 , establece el derecho general a la protección de la vida privada en el artículo 7 y especifica en el artículo 8 que "toda persona tiene derecho a la protección de los datos de carácter personal que le conciernan" (párr. 1). Según el párrafo 2 de esta última disposición, "Estos datos se tratarán de modo leal, para fines concretos y sobre la base del consentimiento de la persona afectada o en virtud de otro fundamento legítimo previsto por la ley. Toda persona tiene derecho a acceder a los datos recogidos que le conciernan y a obtener su rectificación".

La primera pregunta que surge en el contexto de las normas actuales de protección de la privacidad es si el derecho tradicional a la privacidad también abarca los datos contenidos en y generados por nuestras mentes. La respuesta a este dilema no está disponible de manera inmediata, entre otras razones, porque no hay consenso en la literatura jurídica sobre la definición de la privacidad. Esto puede explicarse por el contenido dispar de este derecho, que incluye no solo el derecho a controlar el acceso a la información personal, sino también a nuestros cuerpos y lugares privados. En su artículo seminal, publicado en 1890, Samuel Warren y Louis Brandeis articularon el derecho a la privacidad como "un derecho a ser dejado en paz" (Warren \& Brandeis, 1890). Su principal preocupación era el creciente interés de la prensa amarillista en revelar información personal sobre individuos, incluyendo fotos de personas sin su consentimiento. Este caso específico de privacidad fue desarrollado aún más por Alan Westin y otros autores en la noción más amplia de privacidad informacional, es decir, el control de la información sobre uno mismo. Según Westin, la privacidad puede describirse en términos de nuestra pretensión de determinar por nosotros mismos cuándo, cómo y en qué medida la información sobre nosotros se comunica a los demás (Westin, 1968). Hoy en día, el "derecho a ser dejado en paz" delineado por Warren y Brandeis hace más de un siglo se ha vuelto claramente relevante en áreas muy alejadas de sus preocupaciones originales. Las varias facetas de la comprensión moderna de la privacidad continúan expandiéndose a medida que los desarrollos tecnológicos avanzan. Es muy probable que la neurociencia se convierta en un futuro próximo en una de las nuevas áreas en las que el derecho a la privacidad sea llamado a jugar un papel fundamental e inesperado.

${ }^{4}$ Ver https://ec.europa.eu/info/law/law-topic/data-protection_es

ANÁLISIS FILOSÓFICO 4I(I) - (mayo 202I) 


\section{La aparición del derecho a la privacidad mental}

La ciencia ficción puede ser muy útil para anticipar los desafíos que la ciencia y la tecnología pueden plantear en el futuro, así como las posibles respuestas a los mismos. En una novela del universo Star Trek escrita en 1990, el Capitán Kirk ha sido informado de que un espía peligroso se ha unido subrepticiamente a uno de los grupos que están visitando la nave espacial Enterprise. Kirk quiere desesperadamente identificar al intruso y saber más sobre él y sus planes. Apelando a uno de los miembros de su personal que tiene habilidades telepáticas, Kirk quiere leer las mentes de todos los visitantes. Sin embargo, uno de sus ayudantes le recuerda al capitán que, según la ley, "el derecho a la privacidad mental es un derecho inalienable de todos los ciudadanos de la Federación y no puede ser limitado sin el debido proceso legal" (Mitchell, 1990). Además, "identificar al individuo culpable entre los miembros de esos grupos implicaría (...) invadir la privacidad de un número de personas inocentes" (Mitchell, 1990, p. 150).

El tipo de dilemas descrito en este escenario futurista, que se sitúa en el siglo XXIII, puede convertirse en realidad mucho antes de lo esperado. Desarrollos en las neuroimágenes como los mencionados anteriormente han planteado preocupaciones sobre la ética y la legalidad de la "lectura de la mente". Es cierto que las tecnologías de imágenes funcionales cerebrales no pueden realmente "leer" los pensamientos, sino solo resaltar diferencias en patrones de actividad cerebral durante diferentes tareas, lo cual permite inferir ciertas conclusiones acerca de los pensamientos. Sin embargo, el hecho es que estas nuevas herramientas son cada vez más capaces de determinar con un alto grado de precisión, aunque de manera indirecta, ciertos datos del cerebro que pertenecen a la esfera privada y merecen ser protegidos del escrutinio público.

En las sociedades modernas, las normas de privacidad y protección de datos abarcan el uso y la divulgación de varios tipos de información personal. Dado que los datos decodificados del cerebro de un individuo pueden ser considerados como "información personal" -0 "información personalmente identificable", como se llama en los EE.UU.-, no hay en principio ninguna razón por la que tales datos no puedan ser cubiertos por las regulaciones existentes sobre privacidad y protección de datos. Si cada uno de nosotros tiene una "expectativa razonable de privacidad"

\footnotetext{
${ }^{5}$ La expresión "expectativa razonable de privacidad" fue acuñada por el Supremo Tribunal de los EE.UU. en 1967 para distinguir los registros e incautaciones policiales legítimos de los irrazonables a la luz de la Cuarta Enmienda que protege los derechos de privacidad.
} 
en relación con la información identificable derivada de la sangre o de muestras de saliva, seguramente también tiene una expectativa razonable de privacidad respecto a los datos decodificados de la propia mente (Shen, 2013).

Sin embargo, la naturaleza especial de los datos del cerebro, que se relacionan muy directamente con la interioridad más íntima de uno y con su condición de "persona", y la manera particular en la que se obtienen esos datos, sugieren que probablemente se necesitarán salvaguardas específicas en este ámbito. Cabe señalar que las reglas tradicionales de privacidad han sido concebidas para salvaguardar la información "externa" sobre las personas.

La particularidad de los datos neuronales es que la información a proteger no es fácilmente distinguible de la fuente misma que produjo los datos: el procesamiento neuronal del individuo. Esto es lo que podemos llamar el "problema del origen" (the inception problema), que complica el análisis de las cuestiones que están en juego cuando se utilizan los enfoques tradicionales de la privacidad. En otros términos, el futuro neurotecnológico al que nos acercamos requerirá que garanticemos la protección no solo de la información que registramos y compartimos, sino también de la fuente de esa información, ya que podrían ser inseparables. Para poner esto en práctica se necesitan derechos de privacidad y protección de datos más amplios que también puedan aplicarse a un nivel superior y cronológicamente anterior: nuestra actividad neuronal.

Una razón adicional para preocuparse por la privacidad en este ámbito es que las señales del cerebro permiten distinguir o rastrear la identidad de un individuo y son potencialmente vinculables a ese individuo. Algunos registros cerebrales (por ejemplo, las señales registradas por medio de EEG) pueden ser utilizados como identificadores biométrico únicos, de manera similar a las huellas dactilares o el ADN. En 2007, Palaniappan y sus colegas desarrollaron un marco biométrico basado en EEG para la verificación automática de la identidad (Palaniappan $\&$ Mandic, 2007). Desde entonces, se han desarrollado un gran número de sistemas biométricos basados en EEG para el reconocimiento de individuos (Campisi et al., 2012; La Rocca et al., 2012), la autenticación personal (Marcel \& Del Millan, 2007; Palaniappan, 2008), y la identificación de personas (Brigham \& Kumar, 2010; Mohammadi et al., 2006). Sin embargo, a diferencia de otra información identificable, las ondas cerebrales pueden ser potencialmente registradas sin conocimiento del individuo y por lo tanto en ausencia de una capacidad real de la persona de consentir la recopilación y el uso de esa información. Con el creciente mercado de cascos neurológicos portátiles basados en EEG y en ausen- 
cia de una posibilidad real de obtener consentimiento informado para el procesamiento de los registros que generan, es necesario establecer nuevas propuestas de protección para el procesamiento de datos neuronales. La necesidad de proteger la información generada por debajo del umbral del control voluntario requiere del reconocimiento de un nuevo derecho que se adapte específicamente a las características de la información neuronal y a las nuevas posibilidades abiertas por las tecnologías de lectura de la mente.

A la luz de las neurotecnologías emergentes, también es necesario explorar la posibilidad -técnica y legal- de aplicar un filtro al flujo de información del cerebro con el propósito de distinguir la información que conscientemente queremos mantener en privado de la que queremos revelar públicamente. En la actual sociedad de la información se nos pide constantemente que distingamos entre la información privada y la pública: por ejemplo, cuando creamos la página de contacto en nuestro sitio web o cuando decidimos con quién compartir nuestro número de teléfono móvil. La suposición psicológica básica que subyace en este fenómeno es que los adultos competentes tienen la capacidad de filtrar conscientemente el flujo de información e identificar razonablemente los bits de información que deben mantenerse en privado. La privacidad, de hecho, es tanto un derecho como una habilidad. Como habilidad, permite a los individuos o grupos aislarse a sí mismos o a la información acerca de ellos y, por lo tanto expresarse de manera selectiva. Esta idea ha sido ampliamente importada a la esfera de la tecnología de la información, en la que la privacidad se describe a menudo como la capacidad (o la percepción de la capacidad) de controlar la información personal que compartimos, especialmente cuando utilizamos Internet (Dinev \& Hart, 2004). Para poder ejercer esta capacidad de manera significativa necesitamos un medio racional que pueda filtrar el flujo de información y decidir qué revelar. Este medio es el pensamiento, como bien lo captó el famoso adagio de la seguridad informática "el mejor software antivirus es el cerebro".

Basándonos en estos desafíos específicos, argumentamos que los derechos actuales sobre privacidad y protección de datos son insuficientes para hacer frente a los escenarios neurotecnológicos emergentes. En consecuencia, sugerimos el reconocimiento formal del derecho a la privacidad mental, que tiene como objetivo proteger cualquier bit 0 conjunto de información cerebral sobre un individuo registrado por un dispositivo neurológico y compartido a través del ecosistema digital. Este derecho protegería las ondas cerebrales no solo como datos sino también como generadores de datos o fuentes de información. Además, abarcaría 
no solo los datos del cerebro consciente, sino también los datos que no están (o solo parcialmente) bajo el control voluntario consciente. Por último, garantiza la protección de la información del cerebro en ausencia de un instrumento externo para identificar y filtrar esa información. En resumen, el derecho a la privacidad del cerebro tiene como objetivo proteger a las personas del acceso ilegítimo a su información cerebral y prevenir la fuga indiscriminada de datos cerebrales a través de la infoesfera.

Cabe mencionar que las violaciones de la privacidad mental pueden ocurrir también en ausencia de una intrusión directa en el procesamiento neuronal de la víctima. Por ejemplo, los datos del cerebro recogidos para la investigación suelen almacenarse para su análisis en bases de datos y repositorios externos de EEG. De manera similar, los datos neuronales generados por las interfaces cerebro-computadora (BCI) para consumidores son enviados a una aplicación conectada y pueden ser almacenados en la nube $u$ otra forma externa de almacenamiento de datos. En cualquier caso, se puede acceder a estos datos también en ausencia de la persona que los generó y sin intervenir sobre las señales del cerebro de la persona.

\section{¿El derecho a la privacidad mental es un derecho absoluto o relativo?}

La mayoría de los derechos humanos, incluyendo el derecho a la privacidad, son relativos en el sentido de que pueden ser limitados en determinadas circunstancias, siempre que dichas restricciones sean necesarias y constituyan una manera proporcionada de lograr un propósito legítimo. ${ }^{6} \mathrm{Al}$ tratar específicamente el derecho a la privacidad, la Convención Europea de Derechos Humanos establece que este derecho admite algunas restricciones "para la prevención de desórdenes o delitos, para la protección de la salud o moral, o para la protección de los derechos y libertades de los demás" (art. 8, párr. 2). Solo muy pocos derechos, como la libertad de pensamiento, el derecho a no ser sometido a esclavitud o servidumbre, la tortura y los tratos o castigos inhumanos o degradantes son considerados por el derecho internacional como no sujetos a ninguna excepción, es decir, como derechos absolutos. ¿En cuál de las dos categorías debería colocarse al derecho a la privacidad mental?

\footnotetext{
6 "En el ejercicio de sus derechos y libertades, toda persona estará sujeta únicamente a las limitaciones que se determinan por ley con el único fin de asegurar el debido reconocimiento y respeto para los derechos y libertades de los demás y de cumplir con las justas exigencias de la moralidad, el orden y el bienestar general en una sociedad democrática” (DUDH, Artículo 29.2).
} 
¿Puede el acceso no consentido a los datos cerebrales de las personas ser justificado en ciertas circunstancias o debe ser prohibido de modo incondicional? Más concretamente, ¿el derecho a la privacidad mental protege a los individuos de ser obligados por tribunales o por el Estado a someterse a interrogatorios basados en la lectura de la mente?

Paul Root Wolpe ha sugerido que, dada la preocupación por la opresión del gobierno, deberíamos dibujar una línea nítida alrededor del uso de las tecnologías de lectura de mente:

El cráneo debe ser designado como un dominio de absoluta privacidad. Nadie debería ser capaz de sondear la mente de un individuo en contra de su voluntad. No deberíamos permitirlo con una orden de la corte. No debemos permitirlo por razones militares o de seguridad nacional. Deberíamos renunciar a la utilización de la tecnología bajo circunstancias coercitivas, aunque utilizarla pueda servir al bien público (Wolpe, 2009).

Del mismo modo, se ha argumentado que "la lectura mental no consentida es algo que nunca deberíamos realizar" (Stanley, 2012). La idea es que las técnicas de lectura de la mente constituyen "una afrenta fundamental a la dignidad humana" (Stanley, 2012). En consecuencia, "no debemos permitir que los principios de privacidad de nuestra civilización se degraden hasta tal punto que el intento de leer la mente de una persona en contra de su voluntad se considere alguna vez como aceptable" (Stanley, 2012).

¿Están justificados estos llamamientos a favor de una prohibición incondicional de la lectura compulsiva de la mente? ¿O podría ser aceptable este procedimiento en determinadas circunstancias (por ejemplo, cuando nos enfrentamos a un delito grave o a un ataque terrorista)? Como ya se ha mencionado, el derecho a la privacidad no es absoluto sino relativo. La recolección, utilización y divulgación de información privada es permisible cuando el interés público está en juego. Por ejemplo, en muchos países, los exámenes genéticos pueden ser obligatorios cuando se intenta identificar a un criminal. Teniendo en cuenta el carácter no invasivo y la naturaleza indolora de los escáneres cerebrales, hay prima facie buenas razones para pensar que su uso no consentido podría estar justificado, con una orden judicial, cuando haya motivos razonables para creer que un individuo ha cometido un delito grave 0 que está involucrado en la planificación de un delito grave.

Sin embargo, este dilema se vuelve más intrincado cuando es visto no en conexión con cuestiones de privacidad, sino a la luz del principio 
que prohíbe forzar a alguien a declarar contra sí mismo. Este problema surge particularmente cuando los resultados de los escáneres cerebrales no son considerados como mera información sobre los individuos (como el ADN bucal o el derivado de la sangre, las huellas dactilares, etc.), sino como testimonio, porque en este último caso entraría en juego la cláusula de autoincriminación.

La prohibición de la autoincriminación forzada es ampliamente reconocida en todo el mundo democrático como un componente integral de una justicia penal justa. Este principio es una lógica consecuencia de la presunción de inocencia, lo que hace que la carga de la prueba de la culpabilidad recaiga sobre la fiscalía. En otras palabras, las personas sospechosas de un crimen no tienen ninguna obligación de ayudar a aportar pruebas contra ellas mismas. El principio que prohíbe la autoincriminación está muy relacionado con el derecho a permanecer en silencio y puede superponerse con él. Sin embargo, hay una diferencia conceptual entre ambos: mientras que el primero se refiere a la amenaza de coerción para hacer que un acusado ceda cierta información, este último se refiere a la extracción de inferencias adversas respecto del acusado cuando este no testifica o no responde preguntas (Ashworth, 2008).

El derecho a no autoincriminarse está consagrado en el Pacto Internacional de Derechos Civiles y Políticos que estipula que "toda persona acusada de un delito tendrá derecho (...) a no ser obligada a declarar contra sí misma ni a confesarse culpable" (Art. 14(3)(g)). Una disposición similar se encuentra en la Convención Americana sobre Derechos Humanos y en el Estatuto de Roma de la Corte Penal Internacional. ${ }^{7}$ Aunque el Convenio Europeo de Derechos Humanos no se refiere explícitamente al derecho contra la autoincriminación, el Tribunal Europeo de Derechos Humanos (ECtHR) ha repetido en varias ocasiones que este principio está implícito en el derecho general a un juicio justo, que es garantizado por el artículo 6 de la Convención. ${ }^{8}$ En los EE.UU., la Quinta Enmienda protege contra "la coacción [para] probar [un] cargo contra un acusado a partir de su propia boca". Interpretando esta

7 Convención Americana sobre Derechos Humanos, art. 8(2)(g): "Toda persona acusada de un delito tiene el derecho (...) a no ser obligado a declarar contra sí mismo ni a declararse culpable"; Estatuto de Roma de la Corte Penal Internacional, art. 55(1)(a): "En lo que respecta a una investigación bajo este Estatuto, una persona: a) No será obligada a incriminarse a sí misma o a confesar la culpa”. El apartado b) del párrafo 2 del mismo artículo 55 añade que la persona sospechosa de haber cometido un crimen tiene el derecho de "permanecer en silencio, sin que el silencio sea una consideración en la determinación de la culpabilidad o la inocencia".

${ }^{8}$ Funke c. Francia, ECtHR 1993, A n 256-A; John Murray c. Reino Unido, ECtHR 1996-I. 
cláusula, la Corte Suprema de los Estados Unidos introdujo en 1966 la distinción entre ser obligado a proporcionar pruebas reales o físicas (lo cual está permitido) y ser forzado a dar testimonio autoincriminatorio (lo cual está prohibido). ${ }^{9}$

El ECtHR hace una distinción más sutil cuando distingue entre obligar a proporcionar "pruebas reales que tienen una existencia independiente de la voluntad del sospechoso" (por ejemplo, documentos adquiridos en virtud de una orden judicial, muestras de aliento, sangre, orina o tejidos para realizar pruebas de $\mathrm{ADN}$ ) y evidencia que no es verdaderamente "independiente de la voluntad del sospechoso". ${ }^{10}$ Las respuestas a preguntas son los ejemplos más obvios de esta segunda categoría porque son inconcebibles sin la voluntad del sujeto. Sin embargo, en el caso de Funke c. Francia, el ECtHR ha considerado que ser obligado a presentar ciertos documentos (en el caso, los registros bancarios de cuentas en bancos extranjeros, que podrían servir para incriminar al individuo por evasión de impuestos), equivaldría a una infracción del derecho a no autoincriminarse.

Por lo tanto, la lectura de este derecho hecha por el ECtHR puede ser entendida en el sentido de que la cuestión clave no es tanto si las pruebas son reales u orales (es decir, pruebas físicas en lugar de respuestas a preguntas), sino si las pruebas requieren la cooperación activa del individuo o no (Redmayne, 2007). En otras palabras, "este derecho solo cubre la asistencia del sospechoso, la cual no puede ser sustituida por el empleo de fuerza" (Trechsel, 2005).

$\mathrm{Si}$ aceptamos esta interpretación de este principio, la pregunta es entonces si el mero registro de pensamientos y recuerdos -sin ningún testimonio o declaración oral coaccionada- es una prueba que alguien puede verse legalmente obligado a proveer, o si esta práctica requiere necesariamente la "voluntad del sospechoso" y por lo tanto constituye una violación del derecho a la no autoincriminación forzada. Desafortunadamente, es extremadamente difícil dar una respuesta clara a este dilema. En nuestra opinión, el tema tiene que ser objeto de debate público para encontrar un equilibrio adecuado entre los intereses privados y públicos en juego. El dilema es particularmente arduo porque, por un lado, se podría argumentar que los pensamientos y recuerdos son operaciones puramente internas que por sí mismas no pueden ser forzadas y, por consiguiente, la cláusula de no incriminación no sería aplicable a ellos. Sin embargo, por otro lado, si se permiten

${ }^{9}$ Corte Suprema de los Estados Unidos, Miranda c. Arizona, 384 U.S. 436 (1966).

${ }^{10}$ Saunders c. Reino Unido, ECtHR 1996-VI, párrafo 69. 
las técnicas de lectura de la mente entre los procedimientos penales, hay a largo plazo el riesgo de diluir completamente el derecho a la no autoincriminación, especialmente si las técnicas se vuelven más fiables y eficientes de lo que son en la actualidad. Las personas podrían seguir estando formalmente protegidas contra la autoincriminación oral pero no en contra de la fuente misma de tales testimonios: sus propios pensamientos. Como afirma Nita Farahany (2012), la autoincriminación puede ocurrir tanto silenciosamente como en voz alta.

\section{El derecho a la integridad mental}

Las intrusiones en los cerebros de las personas no solo pueden resultar en una violación de su privacidad mental, sino que también pueden tener un impacto directo en su computación neuronal y resultar en un daño directo hacia ellos. Ienca y Haselager (2016) han introducido la noción de brainhacking malicioso para referirse a las actividades neurocriminales que influyen directamente en la computación neuronal de los usuarios de neurodispositivos de una manera similar a como se hackean las computadoras en los crímenes informáticos. Centrándose en las interfaces cerebro-computadora (BCIs), identifican cuatro tipos de brainhacking malicioso basados en los diferentes niveles del ciclo de la BCI donde el ataque puede ocurrir. Tres de estos tipos (esto es, cuando el ataque se produce al nivel de la medición, de la decodificación o de la retroalimentación) pueden implicar la manipulación directa de la computación neuronal de una persona. Los agentes maliciosos pueden añadir ruido o anular la señal enviada al dispositivo con el propósito de disminuir o eliminar el control del usuario sobre la aplicación, o incluso sustituir el control voluntario de la víctima. Por ejemplo, un criminal podría anular la señal enviada por un usuario y tomar control del dispositivo manejado por la BCI (por ejemplo, un Smartphone o una silla de ruedas electrónica) sin el permiso del usuario.

En este tipo de casos, la privacidad mental de los usuarios y la protección de sus datos cerebrales no son los únicos derechos en riesgo. Más bien, la integridad física y mental de la víctima también está en juego. De hecho, la intrusión forzada y la alteración de los procesos neuronales de una persona plantean una amenaza sin precedentes a su integridad mental.

El derecho a la integridad física y mental de la persona está protegido por la Carta de la Unión Europea de derechos fundamentales (artículo 3), afirmando que "toda persona tiene derecho a que se respete su integridad física y mental”. Es comprensible que la Carta enfatice 
la importancia de este derecho en los campos de la medicina y la biología, debido al impacto directo que las tecnologías biomédicas pueden tener sobre la integridad física y mental de las personas. La disposición se centra en particular en cuatro requisitos: el consentimiento libre e informado, la no comercialización de los elementos del cuerpo y la prohibición de las prácticas eugenésicas y de la clonación reproductiva. No se hace referencia explícita a las prácticas relacionadas con la neurotecnología. Este silencio es comprensible si consideramos que la Carta fue adoptada en 2000, cuando el debate sobre las implicaciones éticas y legales de la neurociencia se estaba recién iniciando. Sin embargo, hoy en día, las posibles aplicaciones de la neurotecnología pueden impactar en la integridad personal de una manera que es comparable con el modo en que puede hacerlo la genética y otras prácticas biomédicas. Por esta razón, el marco normativo debe estar al día con los avances neurotecnológicos y extender la protección de la integridad de las personas a esta nueva área.

Proponemos llenar este vacío normativo solicitando una reconceptualización del derecho a la integridad mental. De hecho, mientras que la ECHR y la Carta de los Derechos Fundamentales de la UE consideran a la integridad mental como un derecho a la salud mental, dependiente del derecho a la integridad física entendida como salud física, la neurotecnología apunta a una dimensión más compleja de la integridad mental. La integridad mental en este sentido más amplio no solo debería garantizar el derecho de las personas con enfermedades mentales a acceder a los servicios de salud mental y recibir tratamiento o apoyo psiquiátrico cuando sea necesario. Además de eso, también debería garantizar el derecho de todos los individuos a proteger su dimensión mental de posibles daños.

Este derecho reconceptualizado debería proporcionar una protección normativa específica contra posibles intervenciones habilitadas por la neurotecnología que implican la alteración no autorizada de la computación neuronal de una persona, potencialmente resultando en un daño directo a la víctima. Para que una acción $\mathrm{X}$ califique como una amenaza a la integridad mental, tiene que: i) implicar el acceso directo y la manipulación de las señales neuronales; ii) no estar autorizada es decir, debe producirse en ausencia del consentimiento informado del generador de la señal-; iii) dar lugar a un daño psicológico. A medida que la neurotecnología se convierte en parte del ecosistema digital y la computación neuronal entra en la infoesfera, la integridad mental de los individuos se verá cada vez más amenazada si no se aplican medidas de protección específicas. 
Las amenazas a la integridad mental no se limitan a los ataques cerebrales malintencionados y otras actividades ilícitas similares. Las alteraciones no autorizadas de la computación neuronal de una persona también podrían surgir de aplicaciones militares de la tecnología de las BCIs para la mejora de soldados. Lebedev y otros han descrito que una prótesis controlada neurológicamente podría enviar información táctil de vuelta al cerebro en casi tiempo real mediante el uso de la microestimulación intracortical (ICMS), creando esencialmente una "interfaz cerebro-máquina-cerebro" (Lebedev et al., 2011). Esas intervenciones pueden modificar directamente la actividad neuronal y pueden utilizarse para ejercer algún grado de control sobre tropas de soldados. Por ejemplo, el Comité de Oportunidades en Neurociencia para las Futuras Aplicaciones Militares del Consejo Nacional de Investigación de las Academias Nacionales (Committee on Opportunities in Neuroscience for Future Army Applications of the National Research Council of the National Academies) ha investigado el uso de tecnologías portátiles como la espectroscopia de infrarrojo cercano (NIRS) para detectar deficiencias en los procesos neuronales de un soldado y la estimulación magnética transcraneal (TMS) para suprimir o mejorar los procesos cerebrales individuales (Consejo Nacional de Investigación, 2009). De manera similar, los derechos relacionados con la integridad mental deberían incluirse expresamente entre los derechos de los prisioneros de guerra, para evitar el uso de intervenciones invasivas de lavado de cerebro.

La estimulación cerebral es un dominio adicional en el que el derecho a la integridad mental puede jugar un papel. Con el creciente número de neuroestimuladores portátiles disponibles en el mercado o dispositivos ensamblados de tipo 'hazlo-tú-mismo', existe el riesgo de que la gente pueda hacer un mal uso de estos dispositivos con el consiguiente impacto negativo en su funcionamiento neuronal, lo que debe ser evitado. Por ejemplo, mientras que la estimulación transcraneal de corriente directa (tDCS) para consumidores está diseñada para funcionar de manera segura solo en cierta banda de frecuencia, hay pocas salvaguardias para evitar que los usuarios o a terceros manipulen la frecuencia del dispositivo.

El ámbito médico no está exento de la posible aplicación del derecho a la integridad mental. Las intervenciones que involucran neurotecnología invasiva como la estimulación cerebral profunda (DBS) implican la alteración del procesamiento neuronal del paciente por medio de impulsos eléctricos generados por electrodos. Mientras que este procedimiento proporciona beneficios terapéuticos para pacientes neurológicos 
que no responden a otros tratamientos, también existe la posibilidad de efectos neuropsiquiátricos adversos incluyendo apatía, comportamiento compulsivo y alucinaciones (Mackenzie, 2011). Además, al ser un procedimiento quirúrgico, existe el riesgo de infección, hemorragia y rechazo del neuroestimulador implantado. Por lo tanto, aunque en dicho procedimiento médico el consentimiento informado se obtiene siempre sobre la base de un requisito mínimo de ética médica, aún así hay un riesgo de que la alteración de la computación neuronal posibilitada por la DBS pueda causar un daño desproporcionado en comparación con el beneficio terapéutico. Este alto potencial de efectos adversos es la razón por la que, aunque se ha demostrado cierta eficacia en el tratamiento de afecciones como la obesidad y la anorexia nerviosa, la DBS todavía no está aprobada por la Food and Drug Administration (FDA) de EE.UU. para el tratamiento de esas condiciones. En este contexto, el derecho a la integridad mental está no solo para prevenir el daño, absolutamente concebido, sino para prevenir un daño relativo desproporcionado en comparación con el potencial beneficio terapéutico.

Por último, el creciente campo de la ingeniería de la memoria probablemente represente un desafío para el derecho a la integridad mental. Se han desarrollado varias técnicas para modular (por ejemplo, aumentar o borrar selectivamente) los recuerdos de una persona. Por ejemplo, Nabavi y colegas utilizaron una técnica optogenética para borrar y posteriormente restaurar memorias específicas a través de un láser óptico que selectivamente fortalece o debilita las conexiones sinápticas (Nabavi et al., 2014). Aunque no han alcanzado aún el nivel de la experimentación humana, estos hallazgos tienen un gran potencial para el tratamiento de enfermedades como el Alzheimer y el estrés postraumático (PTSD). Al mismo tiempo, sin embargo, el mal uso de estas técnicas por parte de actores malévolos puede generar oportunidades sin precedentes de manipulación mental y lavado de cerebro. Por ejemplo, criminales podrían borrar selectivamente los recuerdos de los cerebros de sus víctimas para evitar ser identificados por ellas más tarde o simplemente para causarles daño. En un escenario a largo plazo, esta tecnología podría ser utilizada por agencias de seguridad y vigilancia con el propósito de borrar selectivamente recuerdos peligrosos o inconvenientes del cerebro de las personas, como se muestra en la película Men in Black con el llamado neuralizador. Los posibles motivos de la alteración ilícita de la memoria son varios, incluyendo el aumento de la seguridad nacional o ejercer control sobre individuos o grupos.

$\mathrm{Al}$ igual que el derecho a la privacidad mental, también el derecho a la integridad mental puede no ser absoluto. Por ejemplo, se podría 
argumentar utilitariamente que violaciones controladas y temporales del derecho a la integridad mental deben permitirse como una forma de mejora moral para los delincuentes violentos persistentes. En tal sentido, Persson y Savulescu (2008) han sostenido que, si fuera posible desarrollar técnicas biomédicas de mejora moral (moral enhancement) que fueran seguras y efectivas, entonces estas deberían ser obligatorias. Del mismo modo, Ellegaard y Kragh (2015) han argumentado que no solo es moralmente permisible, sino que es moralmente necesario forzar a delincuentes violentos persistentes a someterse a tratamientos de mejoramiento moral, siempre y cuando se demuestre la eficacia de esas intervenciones. Estas posibles excepciones al derecho a la integridad mental obviamente requerirían un amplio debate social para determinar si -y cuándo- tales manipulaciones obligatorias de la dimensión más profunda del ser humano se podrían justificar en beneficio de la sociedad. Si bien el presente trabajo no tiene por objeto tomar posición en el debate sobre el mejoramiento moral, solo queremos destacar que la propuesta de derechos a la privacidad mental y a la integridad mental no implica ipso facto reconocer el carácter absoluto de los mismos.

\section{El derecho a la continuidad psicológica}

Además de la privacidad mental y la integridad mental, también la percepción que las personas tienen acerca de su propia identidad puede ser puesta en riesgo por un uso inadecuado de la neurotecnología emergente. Como hemos visto en la primera sección de este artículo, los dispositivos neuronales pueden ser usados no solo para monitorear el cerebro, sino también para estimular o modular la función cerebral. Por ejemplo, los dispositivos de estimulación transcraneal de corriente directa (tDCS) aplican una corriente constante y baja a un área de interés del cerebro a través de electrodos en el cuero cabelludo con el propósito de modular la función cerebral. Dado que esta estimulación hace que el potencial de reposo de la membrana neuronal se despolarice o hiperpolarice, causa alteraciones en la función cerebral que son potencialmente beneficiosas para pacientes. La estimulación magnética transcraneal (TMS) y la estimulación cerebral profunda (DBS) abren la posibilidad de intervenir sobre la función cerebral de manera aún más sustancial. Dado el aumento de la eficacia terapéutica de tDCS, TMS y DBS, y el rápido avance de la tecnología, es probable que los dispositivos de estimulación cerebral se expandan a grupos psiquiátricos más amplios y, en el caso de los dos primeros, también a la población en general. 
Sin embargo, los cambios en la función cerebral causados por la estimulación cerebral también pueden generar alteraciones en los estados mentales críticos para la personalidad, y por lo tanto pueden afectar a la identidad personal (Decker \& Fleischer, 2008). En particular, se ha observado que la estimulación cerebral puede tener un impacto en la continuidad psicológica de la persona, esto es, un requisito crucial para la identidad personal que consiste en experimentarse a sí mismo persistiendo a través del tiempo como la misma persona (Klaming \& Haselager, 2013). En varios casos reportados en la literatura científica la DBS ha producido cambios de comportamiento como el aumento de la impulsividad y la agresividad (Frank et al., 2007; Sensi et al., 2004) o cambios en el comportamiento sexual (Houeto et al., 2002). Un estudio sobre pacientes tratados con DBS mostró que más de la mitad de ellos articulaban una sensación de extrañeza y desconocimiento de sí mismos después de la cirugía ("Ya no me siento como yo mismo"; "Me siento como un robot" o "No me he encontrado de nuevo a mí mismo después de la cirugía") (Schüpbach et al., 2006). Estudios más recientes han indicado cambios de personalidad en la dirección de mayor impulsividad (Lewis et al., 2015; Pham et al., 2015). En paralelo, las tecnologías de la ingeniería de la memoria pueden impactar en la identidad de una persona al remover, alterar, agregar selectivamente o sustituir los recuerdos individuales que son relevantes para el autorreconocimiento de las personas.

Es claramente una cuestión empírica determinar la frecuencia y la magnitud de estos cambios psicoconductuales y es una cuestión de derecho penal y de responsabilidad civil evaluar el impacto de estos cambios en la capacidad de asumir responsabilidades y obligaciones. Pero la pregunta que nos interesa aquí es si tales cambios de personalidad inducidos por la neuroestimulación o la tecnología de manipulación de la memoria podrían constituir en algunas circunstancias una violación de un derecho humano básico. Esto podría ser teóricamente el caso, por ejemplo, si el paciente es legalmente incompetente (por ejemplo, un niño) y el cambio de personalidad resulta ser psicológicamente perturbador para el individuo. En tales circunstancias, si el representante legal del paciente se negara a consentir la extracción del dispositivo alegando que ha reducido los síntomas de los trastornos neurológicos, se podría considerar que está actuando en contra del derecho del individuo a la continuidad psicológica.

Sin embargo, es más probable que las amenazas a este derecho ocurran fuera del ámbito clínico. En el contexto de organismos de inteligencia y militares, se ha informado que podrían haber tenido lugar viola- 
ciones de derechos humanos en las últimas décadas durante experimentos que involucran electrodos cerebrales, LSD, hipnosis, la creación de los denominados "candidatos manchurianos"11, y la implantación de falsos recuerdos e inducción de amnesia. Muchos de estos experimentos se llevaron a cabo involuntariamente en civiles y sin ninguna supervisión externa, ni autorización del representante legal de los sujetos, ni ningún seguimiento ulterior (Ross, 2007). Los nuevos conocimientos y tecnologías en el campo de la neurociencia ofrecen nuevas y más eficientes posibilidades de llevar a cabo cambios de personalidad no consentidos. Por ejemplo, Pycroft y otros (2016) expresaron la preocupación de que implantes cerebrales como los empleados en la DBS sean vulnerables a ataques de terceros que quieran ejercer un control malintencionado sobre la actividad cerebral de los usuarios. Llamaron "secuestro cerebral" (brainjacking) a este riesgo de modificación de la actividad cerebral de una persona mediante el uso no autorizado de dispositivos neurológicos por parte de terceros (Pycroft et al., 2016). Las consecuencias negativas del "secuestro de cerebros" incluyen: i) el robo de información, que resultaría en una violación del derecho a la privacidad mental; ii) el cese de la estimulación, agotando las baterías de los implantes, induciendo daños en los tejidos y deterioro de la función cerebral, lo que resultaría en violaciones del derecho a la integridad mental. Sin embargo, algunas posibles consecuencias del "secuestro cerebral" como la alteración del control de los impulsos, la modificación de las emociones o el afecto, la inducción de dolor y la modulación del sistema de recompensas, podrían ser logradas incluso en ausencia de cualquier violación de la privacidad o la integridad mental. En esas circunstancias, la modificación no autorizada de la dimensión cognitivo-emocional-afectiva parece poner en juego un tipo diferente de violación de los derechos humanos: la violación del derecho a la continuidad psicológica.

En resumen, el derecho a la continuidad psicológica tiende en última instancia a preservar la identidad personal y la coherencia del comportamiento del individuo, protegiéndolas de la modificación no consentida por parte de terceros. Este derecho protege la continuidad dada por los pensamientos habituales de una persona, sus preferencias y elecciones por medio de la protección del funcionamiento neuronal subyacente. Como Paul Tiedemann señala, nos entendemos como unida-

\footnotetext{
${ }^{11}$ La expresión "Candidato de Manchuria" se refiere a "una persona que ha sufrido (o se cree que ha sufrido) un lavado del cerebro que lo convirtió en un agente subversivo, específicamente un asesino" (Oxford Dictionary). La expresión fue popularizada por la película de 1962 El Candidato de Manchuria, adaptada de la novela de 1959 del mismo nombre de Richard Condon.
} 
des personales y como sujetos y fuentes de actitudes siempre y cuando estas actitudes tengan un nivel mínimo de coherencia. Es por eso que una grave falta de coherencia haría imposible comprenderse a sí mismo (Tiedemann, 2016).

El derecho a la continuidad psicológica puede ser visto como una forma especial del derecho a la identidad resultante de las neurotecnologías. El derecho a la identidad fue desarrollado por el Tribunal Europeo de Derechos Humanos (ECtHR) a partir del derecho a la vida privada incluido en el artículo 8 de la Convención Europea sobre Derechos $\mathrm{Hu}$ manos. ${ }^{12}$ Como hemos visto en la primera sección, el artículo 8 protege contra la intrusión no deseada y prevé el respeto del espacio privado de un individuo. Sin embargo, hay que distinguir entre la privacidad y la identidad personal. Lo que el derecho a la continuidad psicológica pretende evitar no es el acceso sin restricciones a la información del cerebro, sino la alteración inducida del funcionamiento neuronal.

La Declaración Universal de Derechos Humanos también aborda el derecho a tener y desarrollar una personalidad. El artículo 22 afirma que toda persona está facultada para la realización de los derechos indispensables a "su dignidad y el libre desarrollo de su personalidad". Además, el artículo 29 establece que "[t]oda persona tiene deberes respecto a la comunidad, puesto que solo en ella puede desarrollar libre y plenamente su personalidad”. Según Mănuc (2012), los derechos de la personalidad pueden definirse como aquellos que expresan la quintaesencia de la persona humana, y son intrínsecos al ser humano. En este análisis, estos derechos, que de algún modo reconocen el "espíritu" en el individuo, se han desarrollado a partir de cuestiones vinculadas a la privacidad.

Sin embargo, es dudoso que los derechos de la personalidad actualmente reconocidos sean suficientes para hacer frente a las nuevas amenazas a la continuidad psicológica. De hecho, mientras que estos derechos protegen la transición de los estados mentales a la acción, la continuidad psicológica garantiza la protección a un nivel previo: el del funcionamiento neuronal como tal. En el escenario de riesgo presentado anteriormente, el mal uso de la estimulación cerebral no afecta el vínculo entre los procesos mentales y la acción, es decir, la expresión de los estados mentales, sino a los procesos mentales mismos. Para proporcionar este nivel de protección más íntimo, se necesita un nuevo derecho que proteja la continuidad de la vida mental de una persona de la alteración o interrupción abusiva externa.

${ }^{12}$ Goodwin contra el Reino Unido ECtHR (2002) 35, 18 a 90. 
El derecho a la continuidad psicológica está estrechamente relacionado con el derecho a la integridad mental, y puede superponerse con él. Ambos derechos tienen por objeto proteger a las personas de los abusos y alteraciones no consentidas de su dimensión mental. Sin embargo, difieren en la medida en que el derecho a la continuidad psicológica también se aplica a los escenarios emergentes que no implican directamente un daño neuronal o mental. Por el contrario, como hemos visto en la sección anterior, la presencia de daño es una condición necesaria para que una acción pueda calificarse como una violación de la integridad mental de una persona.

Para apreciar esta diferencia, es importante considerar que la continuidad psicológica podría estar amenazada no solo por un mal uso de la estimulación cerebral, sino también por un tipo de intervención menos invasiva o incluso imperceptible. Un buen ejemplo es la publicidad neural inconsciente desarrollada desde el neuromarketing. Como hemos visto en la primera sección, las empresas de neuromarketing están probando técnicas, como la incorporación de estímulos subliminales, con el propósito de obtener respuestas (por ejemplo, preferir el producto A en lugar del B) sin que las personas puedan advertirlo. Esto ha suscitado críticas entre las organizaciones de defensa del consumidor (como, por ejemplo, el Centro de Democracia Digital, en EE.UU.), las cuales han advertido sobre los peligros de la tecnología potencialmente invasiva del neuromarketing. Jeff Chester, el director ejecutivo de la organización, ha afirmado que "aunque históricamente no ha habido regulación de la publicidad para adultos debido a que los adultos tienen mecanismos de defensa para discernir lo verdadero de lo que no lo es", ahora debe ser regulada "si la publicidad está diseñada con el propósito de evitar esas defensas racionales" (Singer, 2010). Nosotros argumentamos que el derecho a la continuidad psicológica puede proporcionar la base conceptual para abordar los problemas señalados por Chester.

Las amenazas potenciales que podrían ser prevenidas por el derecho a la continuidad psicológica también incluyen nuevas formas de lavado de cerebro. Holbrook y otros (2016) utilizaron estimulación magnética transcraneal para modular las regiones del cerebro responsables de los prejuicios sociales y las creencias políticas y religiosas. Sus resultados mostraron que los participantes a quienes se les inhibió temporalmente la actividad en la corteza frontal medial posterior a través de TMS estaban más dispuestos a aceptar críticas a sus propios países que aquellos participantes cuyos cerebros no habían sido modulados. Usando la misma técnica, pudieron aumentar en los participantes la creencia en la vida después de la muerte. Mientras que 
su experimento fue diseñado para mapear los mecanismos neuronales subyacentes a actitudes y creencias de alto nivel, sus resultados muestran que la misma técnica podría ser utilizada para desencadenar un amplio espectro de alteraciones de las actitudes y creencias de una persona. Por ejemplo, agentes malévolos podrían utilizar la neuromodulación para ejercer formas dañinas de control mental. Estos podrían ser líderes religiosos o coordinadores de grupos terroristas que quisieran reclutar y adoctrinar jóvenes, así como líderes de regímenes autoritarios que quisieran imponer la obediencia política y evitar la rebelión. Sin ir tan lejos, las empresas de marketing podrían usar estas técnicas para modular las preferencias y actitudes de los clientes respecto de sus productos.

$\mathrm{Al}$ igual que los dos derechos mencionados previamente, también es posible discutir si el derecho a la continuidad psicológica debe considerarse como absoluto o relativo. Se podría argumentar que algunos cambios de personalidad inducidos por la neurotecnología podrían ser aceptables con respecto a delincuentes violentos persistentes (por ejemplo, violadores o asesinos seriales y pedófilos). La necesidad de proteger al público de individuos potencialmente peligrosos que muy probablemente reincidan si son liberados justificaría tales medidas. Esto sería incluso una buena alternativa para los propios individuos, que podrían evitar de esta manera pasar toda su vida en prisión. Sin embargo, se impone una gran precaución y un amplio debate público antes de autorizar tales intrusiones intencionales en la personalidad de las personas.

\section{Conclusiones}

El volumen y la variedad de aplicaciones de la neurotecnología está aumentando rápidamente dentro y fuera del ámbito clínico y de investigación. La disponibilidad ubicua de neuroaplicaciones más económicas, graduables y fáciles de usar puede abrir oportunidades sin precedentes en la interfaz cerebro-máquina y hacer que la neurotecnología esté muy presente en nuestra vida cotidiana. Esta tendencia tecnológica puede generar inmensas ventajas para la sociedad en términos de beneficio clínico, de prevención de dolencias, de autocuantificación, de reducción del riesgo de decisiones sesgadas, del uso personalizado de la tecnología, de análisis de marketing, de usos con fines militares y de seguridad nacional e incluso una mayor precisión en las decisiones judiciales. Sin embargo, las implicaciones de estas mismas tecnologías desde el punto de vista de la ética y del derecho necesitan ser exploradas. Argumentamos que el marco normativo debe prepararse urgentemente 
para hacer frente a los cambios disruptivos que generan las neurotecnologías en el ecosistema digital y evitar su mal uso o las consecuencias negativas no deseadas de tales desarrollos. Además, dado el carácter fundamental de la dimensión neurocognitiva, entendemos que esa respuesta normativa no debería centrarse exclusivamente en el derecho civil (por ejemplo, en la reparación de los daños causados) sino también a un nivel más fundamental, como es el de los derechos humanos.

En este contexto, hemos sugerido que las neurotecnologías emergentes requieren una reconceptualización de los derechos humanos existentes o incluso la creación de nuevos derechos. En particular, hemos argumentado que los nuevos riesgos colaterales asociados al uso generalizado de la neurotecnología omnipresente, como el brain-hacking malicioso, así como los usos abusivos de la neurotecnología médica, pueden requerir una reconceptualización del derecho a la integridad mental. De hecho, aunque la integridad mental está protegida por la Carta de Derechos Fundamentales de la Unión Europea (artículo 3), este derecho se conceptualiza como un derecho de acceso que protege la salud mental y es complementario al derecho a la integridad física. Sugerimos que en respuesta a las posibilidades de la neurotecnología emergente, el derecho a la integridad mental no debe solo garantizar la protección contra enfermedades mentales o lesiones traumáticas, sino también contra intrusiones neurotecnológicas no consentidas que puedan afectar la mente de las personas, especialmente si causan un daño mental.

Además de esta reconceptualización, hemos argumentado que la creación de derechos neuroespecíficos puede ser necesaria como una estrategia para afrontar posibles usos indebidos de la neurotecnología y como una forma de protección de las libertades fundamentales asociadas a la toma de decisiones de los individuos. En este sentido, apoyamos el reconocimiento de un derecho negativo a la libertad cognitiva, destinado a proteger a los individuos respecto del uso coercitivo y no consentido de tales tecnologías. Además, como solución complementaria, hemos propuesto el reconocimiento de dos derechos neuroespecíficos adicionales: el derecho a la privacidad mental y el derecho a la continuidad psicológica. A ellos se agrega el derecho a la privacidad mental, que aspira a proteger la información privada o sensible en las mentes de las personas contra la colecta, almacenamiento, uso o incluso la eliminación no autorizada de tales datos mentales. A diferencia de los derechos de privacidad existentes, el derecho a la privacidad mental protege la información antes de cualquier externalización extracraneal (por ejemplo, en formato verbal o impreso), así como al generador de dicha informa- 
ción (el procesamiento neuronal de una persona). Como tal, protege la dimensión mental de una persona como el último ámbito de la privacidad de la información en el ecosistema digital. De modo coordinado con esta propuesta, el derecho a la continuidad psicológica protegerá a los sustratos mentales de la identidad de la alteración inconsciente y no consentida por parte de terceros mediante el uso de neurotecnología invasiva o no invasiva.

Todos estos neuroderechos propuestos están mutuamente vinculados. Siendo el sustrato de las demás libertades en este ámbito, la libertad cognitiva -en su sentido positivo- es un prerrequisito de todos los demás derechos neuroespecíficos. Como tal, la privacidad mental, la integridad mental y la continuidad psicológica son algo muy similar a lo que la libertad de pensamiento es a la privacidad, la integridad y los derechos de identidad. Sin embargo, en el sentido negativo de protección contra el uso coercitivo, la libertad cognitiva solo puede abordar en parte los usos no deseados de la neurotecnología emergente. De hecho, las intrusiones ilícitas en la privacidad mental no implican necesariamente coerción, ya que pueden realizarse por debajo del umbral de la experiencia consciente de una persona. Lo mismo ocurre con las acciones que implican un daño a la vida mental de una persona o modificaciones no autorizadas de su continuidad psicológica. Tales acciones también se ven facilitadas por las nuevas neurotecnologías, que permiten intervenir en el procesamiento neuronal de las personas sin que sean conscientes de ello.

Esta propuesta de derechos humanos neuroespecíficos en respuesta a los avances de la neurotecnología es semejante a la propuesta de derechos humanos específicos adoptados en respuesta a los avances de la genética y la genómica, tal como se establece en la Declaración Universal sobre el Genoma Humano y los Derechos Humanos (UDHGHR) y la Declaración Internacional sobre los Datos Genéticos Humanos (IDHGD).

Un extenso debate será necesario para probar la solidez normativa de esta propuesta de expansión de los derechos humanos al ámbito de la neurotecnología. Paralelamente, se requieren futuras investigaciones para determinar las implicaciones de los derechos humanos propuestos en otros niveles como el derecho internacional humanitario, el derecho penal, el derecho de daños, el derecho de propiedad y el derecho de los consumidores. Idealmente, este debate se beneficiará de la participación activa y transversal de expertos legales, neurocientíficos, desarrolladores de tecnología, neuroeticistas y organismos de regulación. 


\section{Bibliografía}

Aharoni, E., Vincent, G.M., Harenski, C.L., Calhoun, V.D., SinnottArmstrong, W., Gazzaniga, M.S., \& Kiehl, K.A. (2013). Neuroprediction of future rearrest. Proc Natl Acad Sci., 110(15), 6223-6228.

Alston, P. (1984). Conjuring up new human rights: A proposal for quality control. Am J Int Law, 78(3), 607-621.

Andorno, R. (2013). Principles of international biolaw: Seeking common ground at the intersection of bioethics and human rights. Bruylant.

Armstrong, B.C., Ruiz-Blondet, M.V., Khalifian, N., Kurtz, K.J., Jin, Z., \& Laszlo, S. (2015). Brainprint: Assessing the uniqueness, collectability, and permanence of a novel method for ERP biometrics. Neurocomputing, 166, 59-67.

Ashworth, A. (2008). Self-incrimination in European human rights law - A pregnant pragmatism? Cardozo Law Review, 30(3), 751-774.

Baron-Cohen, S. (2004). Essential difference: Male and female brains and the truth about autism. Basic Books.

Beitz, C.R. (2011). The idea of human rights. Oxford University Press.

Berlin, I. (1959). Two concepts of liberty: an inaugural lecture delivered before the University of Oxford on 31 October 1958. Clarendon Press.

Biondi, F., \& Skrypchuk, L. (2017). Use your brain (and light) for innovative human-machine interfaces. En I. Nunes (Ed.), Advances in human factors and system interactions (pp. 99-105). Springer.

Boire, R. G. (2003). Mind matters. Journal of Cognitive Liberties, 4(1), 7-10.

Brigham, K., \& Kumar, B. (2010). Subject identification from electroencephalogram (EEG) signals during imagined speech. Documento presentado en Biometrics: Theory Applications and Systems (BTAS), 2010 Fourth IEEE International Conference.

Bublitz, J.-C. (2013). My mind is mine!? Cognitive liberty as a legal concept. En E. Hildt \& A. G. Franke (Eds.), Cognitive enhancement: An interdisciplinary perspective (pp. 233-264). Springer.

Campisi, P., La Rocca, D., \& Scarano, G. (2012). EEG for automatic person recognition. Computer, 45(7), 87-89.

Charo, R.A. (2015). Yellow lights for emerging technologies. Science, 349(6246), 384-385.

Decker, M., \& Fleischer, T. (2008). Contacting the brain-aspects of a technology assessment of neural implants. Biotechnol J., 3(12), 1502-1510. 
Dick, P. K. (2002). The minority report and other classic stories. Citadel Press.

Diggelmann, O., \& Cleis, M.N. (2014). How the right to privacy became a Human Right. Human Rights Law Review, 14(3), 441-458.

Dinev,T., Hart, P. (2004). Internet privacy concerns and their antecedentsmeasurement validity and a regression model. Behav Inform Technol, 23(6), 413-422.

Ellegaard, M., \& Kragh, K. (2015). Moral enhancement and persistent violent offenders. Roskilde University. Philosophy and Science Studies. https://core.ac.uk/download/pdf/43031078.pdf [Consulta: 21 de diciembre 2020].

Fagan, A. (2005). Human rights. Internet Encyclopedia of Philosophy. http://www.iep.utm.edu/hum-rts [Consulta: 29 de marzo 2017].

Fagan, A. (2015). Human rights: Between idealism and realism. Nordic J Hum Rights, 33(3), 274-275.

Farahany, N.A. (2012). Incriminating thoughts. Stanford Law Rev, 64, 351.

Fernández, A., Sriraman, N., Gurevitz, B., \& Ouiller, O. (2015). Pervasive neurotechnology: A groundbreaking analysis of 10,000+ patent filings transforming medicine, health, entertainment and business. SharpBrains.

Frank, M.J., Samanta, J., Moustafa, A.A., \& Sherman, S.J. (2007). Hold your horses: Impulsivity, deep brain stimulation, and medication in parkinsonism. Science, 318(5854), 1309-1312.

Goodenough, O. R., \& Tucker, M. (2010). Law and cognitive neuroscience. Annu Rev Law Soc Sci, 6, 61-92.

Presidential Commission for the Study of Bioethical Issues (2014). Gray Matters. Integrative Approaches for Neuroscience, Ethics and Society, vol. 1. Bioethics Commission.

Greely, H. T. (2009). Law and the revolution in neuroscience: An early look at the field. Akron L Rev, 42, 687.

Habermas, J. (2010). The concept of human dignity and the realistic utopia of human rights. Metaphilosophy, 41(4), 464-480.

Haynes, J.-D., Sakai, K., Rees, G., Gilbert, S., Frith, C., \& Passingham, R.E. (2007). Reading hidden intentions in the human brain. Curr Biol, 17(4), 323-328.

Herff, C., Heger, D., de Pesters, A., Telaar, D., Brunner, P., Schalk, G., \& Schultz, T. (2015). Brain-to-text: decoding spoken phrases from phone representations in the brain. Front Neurosci, 9, 217. https://doi.org/10.3389/fnins.2015.00217

Holbrook, C., Izuma, K., Deblieck, C., Fessler, D. M., \& Iacoboni, M. 
(2016). Neuromodulation of group prejudice and religious belief. Soc Cogn Affect Neurosci, 11(3), 387-394.

Houeto, J., Mesnage, V., Mallet, L., Pillon, B., Gargiulo, M., du Moncel, S.T., \& Cornu, P. (2012). Behavioural disorders, Parkinson's disease and subthalamic stimulation. $J$ Neurol Neurosurg Psychiatry, 72(6), 701-707.

Iacono, W.G. (2008). Accuracy of polygraph techniques: Problems using confessions to determine ground truth. Physiol Behav, 95(1-2), 24-26. https://doi.org/10.1016/j.physbeh.2008.06.001

Ienca, M., \& Haselager, P. (2016). Hacking the brain: brain-computer interfacing technology and the ethics of neurosecurity. Ethics Inf Technol, 18(2), 117-129.

Illes, J. (2003). Neuroethics in a new era of neuroimaging. Am $J$ Neuroradiol, 24(9), 1739-1741.

Klaming, L, \& Haselager, P. (2013). Did my brain implant make me do it? Questions raised by DBS regarding psychological continuity, responsibility for action and mental competence. Neuroethics, 6(3), 527-539.

Koch, W., Teipel, S., Mueller, S., Benninghoff, J., Wagner, M., Bokde, A.L., \& Meindl, T. (2012). Diagnostic power of default mode network resting state fMRI in the detection of Alzheimer's disease. Neurobiol Aging, 33(3), 466-478.

Kozel, F.A., Johnson, K.A., Mu, Q., Grenesko. E.L., Laken, S.J., George, M.S. (2005). Detecting deception using functional magnetic resonance imaging. Biol Psychiatry, 58(8), 605-613.

La Rocca, D., Campisi, P., \& Scarano, G. (2012). EEG biometrics for individual recognition in resting state with closed eyes. Documento presentado en Biometrics Special Interest Group (BIOSIG), BIOSIG-Proceedings of the International Conference of the Biometrics Special Interest Group.

Langleben, D., Hakun, J., Seelig, D., Wang, A., Ruparel, K., Bilker, W., \& Gur, R. (2016). Polygraphy and functional magnetic resonance imaging in lie detection: A controlled blind comparison using the concealed information test. $J$ Clin Psychiatry, 77(10), 1372-1380.

Lebedev, M. A., Tate, A. J., Hanson, T. L., Li, Z., O’Doherty, J. E., Winans, J. A., \& Schwarz, D. A. (2011). Future developments in brainmachine interface research. Clinics, 66, 25-32.

Lefaucheur, J.-P., André-Obadia, N., Antal, A., Ayache, S. S., Baeken, C., Benninger, D. H., \& De Ridder, D. (2014). Evidence-based guidelines on the therapeutic use of repetitive transcranial magnetic stimulation (rTMS). Clin Neurophysiol, 125(11), 2150-2206. 
Lewis, C., Maier, F., Horstkötter, N., Zywczok, A., Witt, K., Eggers, C., \& Moro, E. (2015). Subjectively perceived personality and mood changes associated with subthalamic stimulation in patients with Parkinson's disease. Psychol Med, 45(1), 73-85.

Mackenzie,R.(2011). Who should hold the remote for the new me? Cognitive, affective, and behavioral side effects of DBS and authentic choices over future personalities. Ajob Neurosci, 2(1), 18-20.

Mănuc, L.M. (2012). Features and evolution references to personality rights. Contemp Read Law Soc Justice, 4(1), 360-370.

Marcel, S., Del Millan, J.R. (2007). Person authentication using brainwaves (EEG) and maximum a posteriori model adaptation. IEEE Trans Pattern Anal Mach Intell, 29(4), 743-752.

McClure, S. M., Li, J., Tomlin, D., Cypert, K. S., Montague, L.M., \& Montague, P.R. (2004). Neural correlates of behavioral preference for culturally familiar drinks. Neuron. 44(2), 379-387.

Mirkovic, B., Debener, S., Jaeger, M., \& De Vos, M. (2015). Decoding the attended speech stream with multi-channel EEG: Implications for online, daily-life applications. J Neural Eng., 12(4), 046007.

Mitchell, V. (1990). Enemy Unseen. Simon and Schuster, vol. 51.

Mohammadi, G., Shoushtari, P., Molaee Ardekani, B., \& Shamsollahi, M. B. (2006). Person identification by using AR model for EEG signals. Documento presentado en Proceeding of World Academy of Science, Engineering and Technology.

Moore, A.D. (2010). Privacy rights: Moral and legal foundations. Penn State Press.

Nabavi, S., Fox, R., Proulx, C. D., Lin, J.Y., Tsien, R.Y., \& Malinow, R. (2014). Engineering a memory with LTD and LTP. Nature, 511, 348-352.

National Research Council (2009). Opportunities in neuroscience for future army applications. The National Academies Press.

Nickel, J. W. (1987). Making sense of human rights: Philosophical reflections on the universal declaration of human rights. University of California Press.

Nickel, J. (2014). Human rights. En Zalta, E., (Ed.), The Stanford Encyclopedia of Philosophy. https://plato.stanford.edu/entries/ rights-human/ [Consulta: 21 de diciembre 2020].

Palaniappan, R. (2008). Two-stage biometric authentication method using thought activity brain waves. Int $J$ Neural Syst, 18(01), 59-66.

Palaniappan, R., Mandic, D.P. (2007). EEG based biometric framework for automatic identity verification. J VLSI Signal Process Syst Signal Image Video Technol, 49(2), 243-250. 
Penenberg, A. (2011). NeuroFocus uses neuromarketing to hack your brain. Fast Company. https://www.fastcompany.com/1769238/ neurofocus-uses-neuromarketing-hack-your-brain [Consulta: 21 de diciembre 2020].

Persson, I., \& Savulescu, J. (2008). The perils of cognitive enhancement and the urgent imperative to enhance the moral character of humanity. Int $J$ Appl Philos, 25(3), 162-177.

Pham, U., Solbakk, A.-K., Skogseid, I.-M., Toft, M., Pripp, A.H., Konglund, A.E., \& Dietrichs, E. (2015). Personality changes after deep brain stimulation in Parkinson's disease. Parkinson's Disease. https:// doi.org/10.1155/2015/490507

Powell, C., Munetomo, M., Schlueter, M., Mizukoshi, M. (2013). Towards thought control of next-generation wearable computing devices Documento presentado en International Conference on Brain and Health Informatics.

Pycroft, L., Boccard, S.G., Owen, S.L.F., Stein, J.F., Fitzgerald, J.J., Green, A.L., \& Aziz, T.Z. (2016). Brainjacking: Implant Security Issues in Invasive Neuromodulation. World Neurosurg, 92, 454462. https://doi.org/10.1016/j.wneu.2016.05.010.

Redmayne, M. (2007). Rethinking the privilege against selfincrimination. Oxf J Leg Stud, 27(2), 209-232.

Ross, C.A. (2007). Ethics of CIA and military contracting by psychiatrists and psychologists. Ethical Hum Psychol Psychiatry, 9(1), 25-34.

Schreiber, D., Fonzo, G., Simmons, A.N., Dawes, C.T., Flagan, T., Fowler, J.H., \& Paulus, M.P. (2013). Red brain, blue brain: Evaluative processes differ in Democrats and Republicans. PLoS One, 8(2), e52970.

Schüpbach, M., Gargiulo, M., Welter, M., Mallet, L., Behar, C., Houeto, J., \& Agid, Y. (2006). Neurosurgery in Parkinson disease A distressed mind in a repaired body? Neurology, 66(12), 1811-1816.

Sensi, M., Eleopra, R., Cavallo, M., Sette, E., Milani, P., Quatrale, R., \& Granieri, E. (2004). Explosive-aggressive behavior related to bilateral subthalamic stimulation. Parkinsonism Relat Disord, 10(4), 247-251.

Sententia, W. (2004). Neuroethical considerations: Cognitive liberty and converging technologies for improving human cognition. Ann NY Acad Sci, 1013(1), 221-228.

Sepuldeva, M., Van Banning, T., van Genugten, W. (2004). Human Rights Reference Handbook. University for Peace.

Shen, F. X. (2013). Neuroscience, mental privacy, and the law. Harv JL \& Pub Pol'y, 36, 653-713. 
Singer, N. (2010). Making ads that whisper to the brain. NY Times Mag, 14,14 .

Smith, K. (2013). Reading minds. Nature, 502, 428-430.

Stanley, J. (2012). High-tech "mind readers" are latest effort to detect lies [Comunicado de prensa]. Recuperado de https://www.aclu. org/blog/high-tech-mind-readers-are-latest-effort-detect-lies

Tiedemann, P. (2016). Identity and human rights: Considerations on a human right to identity Right to Identity. Franz Steiner.

Trechsel, S. (2005). Human rights in criminal proceedings. Oxford University Press.

Ulman, Y.I., Cakar, T., Yildiz, G. (2015). Ethical issues in neuromarketing: "I consume, therefore I am!". Sci Eng Ethics, 21(5), 1271-84.

Warren, S.D., \& Brandeis, L.D. (1890). The right to privacy. Harv Law Rev, 15, 193-220.

Westin, A. F. (1968). Privacy and freedom. Washington Lee Law Rev, $25(1), 166$.

Wolpe, P. R. (2009). Is my mind mine? Neuroethics and brain imaging. En V. Ravitsky, A. Fiester, A. Caplan (Eds.), The Penn Center Guide to Bioethics (pp. 86-93). Springer.

Yuan, B. J., Hsieh, C.-H., Chang, C.-C. (2010). National technology foresight research: A literature review from 1984 to 2005. Int $J$ Foresight Innov Policy, 6(1), 5-35.

Recibido el 11 de diciembre de 2020; aceptado el 18 de diciembre de 2020. 